\title{
RETHINKING GENDER EQUALITY IN THE LEGAL PROFESSION'S PIPELINE TO POWER: A STUDY ON MEDIA COVERAGE OF SUPREME COURT NOMINEES (PHASE I, THE INTRODUCTION WEEK)
}

\author{
Hannah Brenner ${ }^{*}$ \\ Renee Newman Knake**
}

Three women now sit on the Supreme Court of the United States, and a fourth recently retired, suggesting the attainment of formal gender equality. Despite this appearance of progress, women remain significantly underrepresented in major leadership roles within the legal profession, where they face extensive gender bias and stereotyping. This gender bias and stereotyping is also leveraged against women who are featured in the media, illustrated vividly by coverage of the most recent Supreme Court nominations. Headlines from mainstream news, "Then Comes the Marriage Question" in the New York Times or "The Supreme Court Needs More Mothers" in the Washington Post, and from the online blog arena, "Elena Kagan v. Sonia Sotomayor: Who Wore it Better?" in AbovetheLaw.com or "Put a Mom on the Court" in TheDailyBeast.com, are just a sampling of those that emerged during the nomination period for Elena Kagan and Sonia Sotomayor, two highly accomplished, well-qualified nominees.

The gendered nature of these and other articles led us to conduct an empirical study using quantitative and qualitative content analysis to examine media coverage of every Supreme Court nominee since Justices Powell and Rehnquist, a starting point selected in light of the feminist movement's influence at the time. Our project sits at the unique interdisciplinary intersection of law, gender studies, mass media, and political science. This Article presents results from the first phase of data analysis, looking at the week following a president's announcement of a nominee, and we report five preliminary findings. In identifying these findings, we assess the gendered portrayals of nominees to the Court, and we reflect upon how this knowledge might motivate the resolution of gender disparity in the legal profession's pipeline to power.

\footnotetext{
* Lecturer in Law \& Co-Director, Kelley Institute of Ethics and the Legal Profession, Michigan State University College of Law; former Executive Director, Center for Women in Law, University of Texas School of Law.

** Associate Professor of Law \& Co-Director, Kelley Institute of Ethics and the Legal Profession, Michigan State University College of Law. This Article was selected as a winner of the 2012 AALS New Voices in Gender Paper Competition, and we thank the judges and participants for helpful suggestions. We are especially grateful to Linda Greenhouse and Deborah Rhode for their encouragement and feedback on this project from its beginning. We thank Kristi Bowman, Ken Dau-Schmidt, and Wenona Singel for their thoughtful comments on early drafts. Finally, we are so very appreciative of the dedication and hard work on this project from Paul Zube, our research assistants Heather Johnson and Abigail Rury, and the MSU Law Library staff, especially Barbara Bean, Brent Doman, and Jane Meland.
} 


\section{INTRODUCTION}

For the first time in history, three women sit concurrently on the Supreme Court of the United States, and a fourth recently retired. The fact that women now represent one-third of the nation's highest judicial body suggests the attainment of formal equality, however, women remain significantly underrepresented in major leadership roles within the legal profession. Gender equality exists in access to education and most entry-level positions, but not when it comes to positions of power. Even with the unprecedented number of women who have served on the Supreme Court, for example, the position of Chief Justice has remained elusive. This disparity is evidenced not only by statistics on the gender of leaders in the law, but also in the media's portrayal of women lawyers who rise to the profession's highest ranks.

Scholars have documented the lack of women lawyers in positions of power over time, and the most recent statistics still evidence dramatic inequality. Consider that ninety-four percent of managing partners ${ }^{1}$ in the nation's largest law firms are men, and less than sixteen percent of equity partners ${ }^{2}$ are women. ${ }^{3}$ Women represent less than twenty percent of general counsels in the Fortune $500,{ }^{4}$ comprise barely twenty percent of law school deans, ${ }^{5}$ and account for less than thirty percent of tenured law school professors. ${ }^{6}$ Only one-third of law review editors-in-chief in the top fifty U.S. law schools are women. ${ }^{7}$ Women currently hold about twenty-three percent of statewide elective executive offices, down five percent from a peak during 1999 to $2001 .^{8}$

1. Most law firms elect one managing partner to oversee and govern the firm.

2. Equity partnerships are prestigious positions reserved for those holding ownership in a firm.

3. Stephanie A. Scharf et al., The Nat'L Ass'N of Women lawyers \& The NaWl Found., Report of the Fourth annual National Survey on Retention and Promotion of Women in Law Firms 2 (2009) [hereinafter NAWL 2009 National SURVEY]; STEPHANIE A. SCHARF \& Barbara M. Flom,

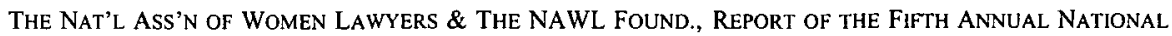
Survey on RETENTION AND PROMOTION OF WOMEN IN LAW FIRMS 3 (2010) [hereinafter NAWL 2010 NaTIONAL SURVEY]. Other studies reach a similar conclusion. See, e.g., Vivia Chen, Looking Into the Equity Box: Women and Partnership Status, THE AM LAW DAILY (Sept. 2, 2010, 6:00 AM), http://amlawdaily.typepa d.com/amlawdaily/2010/09/womenequity.html ("First, women make up only 17 percent of partners at the firms we surveyed, even though they have represented about 51 percent of law school graduates in the last 20 years. Second, of the women partners who work at multitier firms, 45 percent have equity status.").

4. aBa Commission on Women in the Profession, a Current Glance at Women in the LaW 2009, at 2 (2009).

5. Id. at 3 .

6. See AM. BAR ASS'N, FACULTY INFORMATION BY GENDER 2008-2009, at 2-3 (2010), available at http://www.abanet.org/legaled/statistics/charts/facultyinformationbygender.pdf (indicating that of 4,620 tenured faculty members, only 1,364 are women).

7. Women on Law Review: A Gender Diversity Report, Ms. JD (Aug. 23, 2010, 9:15 AM), http://msjd.org/women-law-review-gender-diversity-report (" $[W]$ hile overall percentages of women members of these law journals $(44.3 \%)$ and women in leadership positions ( $46.2 \%)$ correlates strongly to the number of women awarded law degrees during the same time period $(45.7 \%$ in 2008$)$, the number of women editors-in-chief is disproportionately low (33\%).").

8. Jennifer Horne Boyter, COUnCil of State Gov'ts, Capitol Facts and Figures: Women in State Governments 1 (2010); Eagleton Institute of Politics, Facts, CTr. FOr AM. WOMEN \& POLITICS, http://www.cawp.rutgers.edu/fast_facts/levels_of_office/statewide.php (last visited Mar. 5, 2012). Only six states currently have female governors, and in twenty-seven states no woman has ever held the position. BOYTER, supra, at l. Also notable is the 2010 North Carolina Supreme Court election, which resulted in a 
Nationally, the figures for women serving in Congress are even lower, at less than seventeen percent. ${ }^{9}$ In the judicial branch, women comprise thirty-one percent of the judges serving on a state supreme court or its equivalent. ${ }^{10}$ Only five states and the District of Columbia have a majority of women on their highest court, and many states have only one. ${ }^{11}$ Even among the lawyers who argue cases before the Supreme Court, only about fifteen percent are women. ${ }^{12}$ When factoring in race and ethnicity, the picture becomes even grimmer. ${ }^{13}$

The lack of female lawyers in positions of leadership and power was attributable for many years to a limited pool of available women in the profession, but this no longer is the case. Women graduate from law school in approximately equal numbers to men, and have done so for over a decade. Since 1985 at least thirty-five percent of all law graduates have been women. ${ }^{14}$ Yet across the board, women remain excluded from powerful positions in the legal profession, whether on the law review, in the corner office, or on the bench. We certainly are not the first to make this observation. Scholars and practitioners struggle to address the phenomenon in a variety of ways, and one common theme pervades: women face extraordinary barriers to advancement. Solutions remain elusive.

majority of women on the court for the first time in the state's history. Editorial, With a Majority of Women, State's Top Court Hits Milestone, NEws \& RECORD (Greensboro, N.C.), Nov. 10, 2010, at A 10

9. Eagleton Institute of Politics, Facts on Women in Congress 2011, CTR. FOR AM. WOMEN \& PoLITICS, http://www.cawp.rutgers.edu/fast_facts/levels_of_office/Congress-CurrentFacts.php (last visited Mar. 5, 2012).

10. BOYTER, supra note 8 , at 1 ("Currently, 4,521 women serve as state court judges, representing 26.4 percent of the total 17,108 positions. This includes 111 women who serve on a state final appellate jurisdiction court ...." (footnote omitted) (paragraph break omitted)).

11. Diversity of the Bench, AM. JUDICATURE SOC'Y, www.judicialselection.us/Judicial_selection/bench diversity/index.cfm (last visited Mar. 5, 2012) (citing Gender Ratio Summary, in THE AMERICAN BENCH: JUDGES OF THE NATION (Diana R. Irvine et al. eds., 20th ed. 2010)). The states with a majority of women serving on the highest court are California, North Carolina, Ohio, Tennessee, and Wisconsin. Id.

12. Jessica Gresko, Few Women Argue Before Supreme Court, L.A. TIMES, Jan. 23, 2011, at A14.

13. See, e.g., Diversity of the Bench, supra note 11 (providing statistics indicating that many states have no minorities on their highest court); see also Susan J. Carroll, Women in State Government: Historical Overview and Current Trends, in THE BOOK OF THE STATES 442-43 (2007) (noting that although the first woman was elected to the Ohio Supreme Court in 1922, followed by a second woman elected to the Arizona Supreme Court in 1960, it was not until 2003 that a Latina became the chief justice of the New Mexico Supreme Court and not until 2005 that the first African-American woman "preside[d] over a state court of last resort"). For a comprehensive analysis addressing why "blacks have had little success breaking into the upper echelons of the elite bar," see David B. Wilkins \& G. Mitu Gulati, Why Are There So Few Black Lawyers in Corporate Law Firms? An Institutional Analysis, 84 CALIF. L. REV. 493, 497 (1996). Though Professors Wilkins and Gulati wrote this article fifteen years ago, recent statistics reveal that their observations remain true today. See, e.g., RONit DINOVItZER ET AL., NALP FoUnd. \& AM. BAR Found., AFTER THE JD: FiRST RESULTS OF A NATIONAL STUDY ON LEGAL CAREERS 64 (2004) (noting that median salaries for black lawyers are generally lower than those of other groups); see also ABA COMM'N ON WOMEN IN THE PROFESSION, FROM VISIBLY INVISIBLE TO VISIBLY SUCCESSFUL: SUCCESS STRATEGIES FOR LAW FIRMS AND WOMEN OF COLOR IN LAW FIRMS (2008) (providing specific strategies for law firms and lawyers to improve diversity based on research conducted with twenty eight women of color partners in national law firms); ABA COMM'N ON WOMEN IN THE Profession, VISIBle INVISIBILITY: WOMEN OF COLOR IN LAW FIRMS (2006) (identifying specific barriers and obstacles facing women of color lawyers).

14. NAWL 2010 NATIONAL SURVEY, supra note 3 , at 1. 
The nation's four female Supreme Court Justices shattered one of the remaining glass ceilings. ${ }^{15}$ Yet despite their individual successes, they remain subject to significant stereotypes and bias. One place where this plays out in colorful, if not disturbing, ways is in media coverage of nominees to the Court. Headlines from mainstream news- “"Then Comes the Marriage Question" in the New York Times ${ }^{16}$ or "The Case for More Mothers" in the Washington Post, ${ }^{17}$ and from the online blog arena, "Elena Kagan v. Sonia Sotomayor: Who Wore it Better?" in AbovetheLaw.com ${ }^{18}$ or "Put a Mom on the Court" in TheDailyBeast.com ${ }^{19}$-are just a sampling of those that emerged during the nomination periods for Elena Kagan and Sonia Sotomayor. Criticism leveraged against the two women regarding beauty, fashion sensibility, marriage, motherhood status, and sexuality accompanied the usual assessment of qualifications and experience for Supreme Court nominees.

As these articles and blog posts appeared during the Supreme Court nominations for Sotomayor and Kagan, we took notice. We clipped articles from the newspaper, much as Sandra Day O'Connor did in the early 1970s when the press speculated about the possibility of a woman nominee to the Court (though ultimately the nominations went to Powell and Rehnquist). ${ }^{20}$ We exchanged links to blog posts and other online discussions and typed lengthy emails to one another, reacting to what we read. ${ }^{21}$

15. Although the number of women who have served on the Supreme Court is unprecedented, a woman has yet to serve in the capacity of Chief Justice, a position of ultimate prestige and power. Similar to the executive office of the United States, which has not yet seen a female president or vice-president, the position of Chief Justice perhaps represents the ultimate glass ceiling. Despite Hillary Clinton's optimistic remark after her unsuccessful bid for the Democratic nomination that, "[a]lthough we weren't able to shatter that highest, hardest ceiling this time, thanks to you, it's got about 18 million cracks in it," the reality is that women have yet to break through. Peter Baker \& Jim Rutenberg, The Long Road to a Clinton Exit, N.Y. TIMES, June 8, 2008, at A1.

16. Laura M. Holson, Then Comes the Marriage Question, N.Y. TIMES, May 16, 2010, at ST6 ("For the second time in a year, a childless, unmarried woman in her 50 s has been nominated to be a justice on the Supreme Court and the critics have come out swinging.").

17. Ann Gerhart, The Case for More Mothers, WASH. POST, May 16, 2010, at B01 ("But in selecting Kagan, Obama ensured that one key demographic would actually lose representation on the court, compared with its membership just a few years ago: mothers, a category in which 80 percent of American women eventually land.").

18. David Lat, Elena Kagan v. Sonia Sotomayor: Who Wore it Better?, ABove The LAW (June 28, 2010 , 10:41 PM), http://abovethelaw.com/2010/06/elena-kagan-v-sonia-sotomayor-who-wore-it-better ("Solicitor General Kagan decided to wear the same outfit that then-Judge Sonia Sotomayor wore to day one of her confirmation hearings: an electric blue blazer over a black blouse.").

19. Peter Beinart, Put a Mom on the Court, The DaILY BEAST (Apr. 25, 2010, 8:43 PM), http://www.thedailybeast.com/blogs-and-stories/2010-04-26/put-a-mom-on-the-court ("I hope Barack Obama puts another woman on the Supreme Court. And this time, I hope it's a woman with kids.”).

20. See Joan Biskupic, Sandra day O'Connor: How the First Woman on the Supreme Court BECAME ITS MOST INFLUENTIAL JUSTICE 40-41 (2005) ("O'Connor had been clipping news stories that speculated about the possibility of Nixon's choosing a woman. The president had forwarded the name of Mildred Lillie, a California state court of appeals judge, along with the name of five other potential nominees, to the American Bar Association for its traditional advisory review. . . But a month earlier, just as O'Connor happened to be drafting her letter to the president, Nixon had confided to aides . . that he really did not want a woman justice.").

21. After embarking on this project, we were not surprised to learn that others were engaging in similar conversations. For example, shortly after posting an abstract for this Article on SSRN (the Social Science 
The gendered nature of the headlines and related photographs, even the particular location of the article about a nominee on the newspaper page or the photo selected, led us to ask a number of questions. What are the similarities and differences in subject matter of news coverage for nominees? What sort of introduction do they receive in the first articles that appear after their nomination is announced? Does coverage differ between male and female nominees during their respective confirmation hearings? How might disparate treatment in media coverage be emblematic of the gender imbalance that persists in other positions of power within the legal profession or the employment realm generally? Could a more systematic analysis of these media depictions help advance the conversation about the remaining gender inequality in the legal profession and beyond? The importance and complexity of these questions warranted study and analysis beyond what our anecdotal clipping of articles and exchanging of blog posts could possibly reveal. This led us to embark upon an empirical study of the media's depiction of Supreme Court nominees with an interdisciplinary focus, situating our work at the unexplored intersection of law, political science, communications/media studies, sociology, and gender.

To conduct this study, we created the Supreme Court Nominee Media Collection, which contains articles from the New York Times and the Washington Post about every Supreme Court nominee ${ }^{22}$ since Rehnquist and Powell, who were both nominated and confirmed in late 1971 and sworn in during the first weeks of 1972. We selected this starting point mindful of the feminist movement's influence at the time. ${ }^{23}$

We are not familiar with any major research endeavor that attempts to evaluate the gendered media portrayal of Supreme Court nominees in the manner contemplated by our Media Study. In some ways this is rather surprising because "one of the most significant public discussions of the Court happens when a vacancy on the high bench is being filled." ${ }^{24}$ Until very recently, however, the question of gender and the Court was one of limited significance because there were no women on the Supreme Court to study. ${ }^{25}$ Now that we are closer to a numerical tipping point ${ }^{26}$ with gender

Research Network), we received an email from Linda Greenhouse, a professor at Yale Law School and former Supreme Court correspondent for the New York Times, that she recently heard her students discussing these issues. Email from Linda Greenhouse, Professor, Yale Law School, to Hannah Brenner, Lecturer in Law, Michigan State University College of Law (Dec. 1, 2010, 10:08 AM EST) (on file with authors).

22. In determining whether to include an individual as a nominee, we selected the men and women whose names were submitted to Congress by the President as his official nominees. See Supreme Court Nominations, Present-1789, U.S. SENATE, http://www.senate.gov/pagelayout/reference/nominations/Nominati ons.htm (last visited Mar. 5, 2012).

23. The Equal Rights Amendment was passed by both houses of Congress in 1972, and Roe v. Wade was reargued before the Supreme Court in 1972, with the decision handed down in January 1973. See infra Part II.C.4 for a discussion of the reasons for beginning the study with the Powell and Rehnquist nominations.

24. Keith J. Bybee, Will the Real Elena Kagan Please Stand Up? Conflicting Public Images in the Supreme Court Confirmation Process, 1 WAKE FOREST J.L. \& POL'Y 137, 140 (2011) (citing Jennifer Agiesta, Majority Back Kagan Confirmation as Interest Wanes, WASH. POST (July 20, 2010, 6:00 AM), http://voices.w ashingtonpost.com/behind-the-numbers/2010/07/majority back kagan confirmati.html).

25. Elaine Martin, Bethany Sneed, and Claudia Petrescu make a similar observation in their study on gender and state courts: "Th[e] gap in knowledge is certainly understandable given the historical underrepresentation of women in judicial office." Elaine Martin et al., Gender and State Courts: The More Things Change, the More They Stay the Same 1 (Apr. 20, 2006) (unpublished manuscript), available at http://citation. 
representation on the Court, it is an appropriate time to explore the messages conveyed by the media about Supreme Court nominees. There are few opportunities to gain public glimpses into the legal profession, and it is our intent that this project will not only contribute to an understanding of gender inequality but also that this understanding will be used to ultimately facilitate change in the landscape for women in the legal profession.

Using the study findings as a modern lens through which to view gender and power in the legal profession, this project assesses bias, stereotypes, tokenism, and double binds experienced by female lawyers as they strive to attain positions of power in the legal profession and beyond. Our decision to focus on gender and the media's treatment of Supreme Court nominees is not meant to suggest that race is not equally concerning, nor to deny the complexity of interlocking forms of oppression. Indeed, a related purpose of this project is to facilitate research and analysis of issues beyond gender, including race and ethnicity. ${ }^{27}$

We intend to explore the data collected through our Media Study in phases. Phase One is devoted to analysis of coverage by major news media during the first week that follows the announcement of a nominee by the President (i.e., the introduction week) ${ }^{28}$ Later phases of this project may examine the same media sources during different time

allacademic.com/meta/p_mla_apa_research_citation/1/3/7/6/8/pages 137687/pl37687-1.php.

26. Some scholars suggest that "at a participation rate of $35 \%$, women cease to be 'token' employees, and become a 'minority group' capable of affecting the culture and practices of an organisation." Hilary Sommerlad, The Myth of Feminisation: Women and Cultural Change in the Legal Profession, 1 INT'L J. LEgal Prof. 31, 33 (1994). Sommerlad theorizes that it "may be exactly a fear of this possibility which reduces the likelihood of women's substantial progression." Id. Indeed, Rosabeth Moss Kanter's early work on women in organizations argued that it requires more than just one or two token minorities to change organizational dynamics: "It would appear that larger numbers are necessary for supportive alliances to develop in the token context." ROSABETH MOSS KANTER, MEN AND WOMEN OF THE CORPORATION 238 (1977). The shift in organizational dynamics to include a greater number of minorities is sometimes referred to as the achievement of critical mass. "Research has demonstrated that achieving critical mass (at least one-third) of women in leadership is essential ..." THE WhITE House Project, THE WhITE House Project RePORT: BENCHMARKING WOMEN'S LEADERSHIP 5 (2009). Marcia Greenberger, Co-President of the National Women's Law Center, recently spoke to this phenomenon: "With Elana Kagan's confirmation, there will be three women Justices on the court for the first time in history, nearly thirty years after the now-retired Justice Sandra Day O'Connor broke through the glass ceiling to become the first woman Justice. This important first for the Supreme Court is one more step toward the time when women Justices will no longer be viewed as the exception, but rather part of what is normal and routine." Press Release, Nat'l Women's Law Center, Judiciary Committee Approves Kagan's Nomination: NWLC Applauds the Committee's Action, Urges the Senate to Vote Quickly (July 19, 2010), http://www.nwlc.org/press-release/judiciary-committee-approves-kagans-nomin ation.

27. We intend to explore intersections of gender and race/ethnicity in our future work. For a fascinating analysis of African-American press coverage during the Clarence Thomas nomination, see Kathleen FearnBanks, African-American Press Coverage of Clarence Thomas Nomination, 15 NEwSPAPER RES. J., 98, 112 (1994) (concluding that in "coverage of Thomas, the newspapers' tradition of support of African Americans was challenged by the tradition of crusading for civil rights").

28. We focused on this period for our first phase of research because the sample offers a sufficient body of data to conduct a rigorous content analysis and also allows us to contrast media coverage between the introduction period and other points in time during the nomination process. Selection of this time period is supported in the literature. See infra notes 231-34 and accompanying text for a discussion of use of the introduction week time period. 
periods, like the confirmation hearings or the full period from the announcement of the nomination until the date of confirmation or withdrawal, as well as address additional media sources, such as online blog coverage. The results from Phase One are addressed in this Article. We plan to take up the results from the next phases in future writing.

Our Media Study invites the reader to rethink gender equality in the legal profession by examining what the media's depiction of Supreme Court nominees reveals about the pipeline to power. This Article proceeds as follows. Part II situates our work in the existing literature that surrounds the multiple points of intersection inherent in this project. We survey scholarship from the disciplines of law, political science, communications/mass media, sociology, and gender. Our work is particularly informed by academics that have written extensively about the various kinds of bias, stereotypes, and double binds ${ }^{29}$ experienced by female professionals, and especially female lawyers, as they endeavor to advance their careers. Additionally, we discuss the gendered structures of reporting and news media, and we explore the ways in which researchers and scholars have grappled with the intersections of gender and judging. We then examine literature on the effects of media and media coverage of the Supreme Court as well as the confirmation process generally. Part II also provides an overview of the project, and explains how we went about the creation of a unique dataset for conducting a comprehensive quantitative and qualitative content analysis the media's depictions of Supreme Court nominees.

Part III offers preliminary observations from Phase One of the Media Study, which focused on the way that news media introduces the nominee to the public. To capture this, we relied on data collected from coverage during the first seven days after the nomination is announced and reflected upon how this data supports or refutes a series of hypotheses that we devised when embarking on this study. We identified five preliminary findings that emerged during the introduction week:

- Preliminary Finding 1: Female nominees receive more coverage (in terms of quantity and length of articles) than male nominees during the introduction week.

- Preliminary Finding 2: The gender or sexuality of female nominees is mentioned more frequently than the gender or sexuality of male nominees during the introduction week.

- Preliminary Finding 3: The limited sample of articles tends to show that the appearance of female nominees is mentioned more frequently than the appearance of male nominees, but more data is needed.

- Preliminary Finding 4: The limited sample of articles from the introduction week reveals that the family life of female

29. The term "double bind" was described in the 1980 s by philosopher Marilyn Frey as referring to "situations in which options are reduced to a very few and all of them expose one to penalty, censure or deprivation." MARILYN FRYE, THE POLITICS OF REALITY: ESSAYS IN FEMINIST THEORY 2 (1983). More recently, communications scholar Kathleen Hall Jamieson developed a comprehensive framework of the myriad ways in which double binds manifest for women. See generally KATHLEEN HALL JAMIESON, BEYOND THE DOUBLE BIND: WOMEN AND LEADERSHIP (1995). 
nominees tends to be mentioned more frequently than the family life of male nominees, but more data is needed.

- Preliminary Finding 5: The articles are more likely to be written by male journalists than female journalists during the introduction week.

These findings provide a framework for rethinking equality in the legal profession's pipeline to power and establish the groundwork for the next phases of our content analysis.

\section{The SUPREME COURT NOMINEE MEDIA STUDY}

\section{A. Literature Review}

To appreciate the novelty and significance of our preliminary findings, we first must situate the Media Study in the context of existing scholarship on specific characteristics of women's advancement in the legal profession, the role of gender in the production and substance of media, the intersections of gender and judicial decision-making, and coverage of the Supreme Court.

Our observation that women shattered the glass ceiling by reaching positions once thought unattainable, yet remain subject to significant stereotypes and bias, is certainly not new. Scholars and practitioners alike struggle to explain this phenomenon and to develop innovative solutions. Numerous conferences, research studies, books, and articles are devoted to the issue, whether in law, political science, communication studies, or other fields. ${ }^{30}$ For example, law professor and founding director of the University of Maryland's Women, Leadership, and Equality Program, Paula Monopoli, proposes a radical rethinking of judicial selection to the Supreme Court through implementation of statutory reform or a constitutional amendment to require gender parity. ${ }^{31}$ As another example, a group of the nation's leading women lawyers employed a different approach while gathered for the inaugural Women's Power Summit on Law

30. Deborah Rhode and Barbara Kellerman make a similar point in their article, The State of Play, where they observe that "[w]omen's underrepresentation in positions of power generates an increasing array of committees, commissions, consultants, centers, conferences, and commentary." Deborah L. Rhode \& Barbara Kellerman, Women and Leadership: The State of Play, in WOMEN AND LEADERSHIP: THE STATE OF PLAY AND STRATEGies FOR ChANGE 1 (Barbara Kellerman \& Deborah L. Rhode eds., 2007) [hereinafter WOMEN AND LEADERSHIP]. For a small sample of conferences devoted to women, power, and leadership in the legal professions, see Mona Harrington et al., AdvanCING WOMEn IN the Profession: ACtion Plans for WOMEN's BAR AsSOCIATIONS 3 (2007); Women's Power Summit on Law \& Leadership (Apr. 29, 2009), http://www.utexas.edu/law/centers/cwil/cwl-events/2009-summit/schedule.html. Cited throughout this Article are many of the research studies, books, and articles written on the subject as well.

31. Paula A. Monopoli, Gender and Justice: Parity and the United States Supreme Court, 8 Geo. J. GENDER \& L. 43, 46-48 (2007). Other scholars have taken a different approach. See, e.g., Rosalind Dixon, Female Justices, Feminism, and the Politics of Judicial Appointment: A Re-examination, 21 YALE J.L. \& FEMINISM 297, 336-38 (2010) (suggesting that the focus on gender parity is misguided, arguing instead for the addition of judges who have a feminist ideology). Dixon acknowledges feminists' desire for equal numbers of women in the judiciary but concludes that "feminists must also weigh these benefits associated with the mere presence of a female justice on the Court against the importance of a justice's substantive approach to issues of central concern to feminists, such as abortion, pay equity, sex discrimination, sexual harassment, and an ongoing dialogue about the meaning of gender equality under the Equal Protection Clause." Id. at 336. 
and Leadership in 2009. ${ }^{32}$ They drafted a blueprint for change, the Austin Manifesto for Women in Law, outlining a series of principles and pledges toward the goal of achieving "gender parity in positions of leadership, influence, and responsibility in the legal profession." 33

One area entirely unexplored with respect to its bearing on the gender disparity in legal positions of power is the media's coverage of the Supreme Court. Political scientists and communication scholars have long examined the interplay of gender, media, and politics. Their focus, however, has been primarily on elected legislative, gubernatorial, and presidential candidates, exploring issues like how the media affects political campaigns, voting behavior, and intricacies of serving in elective office. ${ }^{34}$ Only occasionally do they pay attention to the judiciary, usually in the context of state judicial elections. ${ }^{35}$ Political science professor Sally Kenney observes that "[r]eview essays on women and politics, textbooks, and even the editorial boards of our journals

32. The Summit, convened by the Center for Women in Law at the University of Texas School of Law in April 2009, included managing partners from the nation's largest law firms, general counsels from Fortune 500 companies, state supreme court justices, federal district court judges, law school deans, state bar presidents, and other powerful women lawyers. See Center for Women in Law, Women's Power Summit on Law and Leadership, THE UNIV. OF TEX. AT AUSTIN SCH. OF LAW, http://www.utexas.edu/law/centers/cwil/cwl -events/2009-summit/schedule.html (last visited Mar. 5, 2012).

33. UNIV. OF TEX. SCH. OF LAW, CTR. FOR WOMEN IN LAW, AUSTIN MANIFESTO ON WOMEN IN LAW 2 (2009), available at http:/www.utexas.edu/law/centers/cwil/cwl-events/2009-summit/austin_manifesto.pdf. Signatories to the Manifesto include prominent leaders like Linda Addison, partner in charge, Fulbright \& Jaworski L.L.P. (New York); Catherine Lamboley, former general counsel and vice-president, Shell Oil Company (Lamboley was the first woman to serve as general counsel at Shell, and her tenure is remembered for its groundbreaking leadership surrounding diversity issues); Ilene Lang, CEO, Catalyst, Inc., an international organization that works to expand opportunities for women and business; former Chief Justice of the Arizona Supreme Court, Ruth V. McGregor; Cynthia Nance, former Dean of the University ArkansasFayetteville Law School (Dean Nance was the first woman and first African-American dean at Arkansas). A full list of signatories to the Manifesto can be found at http://www.utexas.edu/law/centers/cwil/events/2009. summit/austin_manifesto.html (last visited Mar. 5, 2012).

34. See, e.g., Kim Fridkin Kahn, The Political Consequences of Being a Woman (1996). Kahn's research explores how gender stereotypes affect political campaigns. By analyzing news coverage, campaign advertisements, and surveys of voters, she attempts to answer the question of why so few women are represented in political positions of power. For other discussions on issues of media and press coverage of women candidates versus their male counterparts, see DIANNE G. BYSTROM ET AL., THE MILLENNIUM ElECtION: COMMUNICATION IN THE 2000 CAMPAiGN (Lynda Lee Kaid et al. eds., 2003) (exploring media coverage of campaigns and candidates' own advertising in the 2000 elections); ERIKA FALK, WOMEN FOR PrEsidenT: MEdia BIAS IN NINE CAMPAIGNS 15 (2d ed. 2010) (concluding that "[p]ress coverage [of women candidates] is often biased and prejudiced and not much better today than in 1872"); Dianne Bystrom \& Lynda Lee Kaid, Are Women Candidates Transforming Campaign Communication?: A Comparison of Advertising Videostyles in the 1990s, in WOMEN TRANSFORMING CONGRESS 146, 147 (Cindy Simon Rosenthal ed., 2002) (analyzing and comparing male and female congressional candidates' television commercials for tone, appearance, and issues); Pippa Norris, Introduction to WOMEN, MEDIA, AND Politics 1 (Pippa Norris ed., 1997) (exploring the question whether "media coverage of women in America reinforces rather than challenges the dominant culture, and thereby contributes toward women's marginalization in public life").

35. Much of the work done on the judiciary surrounds state judicial campaigns. See, e.g., Elaine Martin, Feminist Judges: Challenging the Status Quo, in THE IMPACT OF WOMEN IN PUblic OfFICE 205 (Susan J. Carroll ed., 2001). 
tend to include law and courts as, at best, an afterthought or leave it out altogether." 36 Academics in law and gender studies have also examined these issues, but primarily emphasize the gender disparity on the ground, looking, for example, at the number of women holding certain positions in legal employment generally or, more recently, questioning the statistical disparity in positions of leadership and power.

Studying the media's depiction of Supreme Court nominees is fruitful for many reasons. First, this study is important because "citizens utilize the mass media as a method of learning about and participating in the activities of their government," including citizens' understanding of Supreme Court nominees. ${ }^{37}$ Second, the nomination process has become a high stakes game for multiple parties to the process, including the nominees themselves, the White House, and the Senate, ${ }^{38}$ as well as the media itself. ${ }^{39}$ In other words, the nomination process has "transformed into a mediaoriented process." ${ }^{40}$ Third, the media holds the power to shape if not alter the course of a nomination. ${ }^{41}$ For example, "[t] he Senate Judiciary Committee could effectively ignore Anita Hill's charges concerning Clarence Thomas before they became public knowledge, but certainly not after."42 Our data evidenced that the media also played a notable role in derailing the confirmation of nominees Robert Bork and Harriet Miers.

Despite the value in such possible investigations, our focus is not directed specifically at any of these ends. Rather, we intend to show that an empirical assessment of the media's attention to Supreme Court nominees can play an integral role in advancing the conversation about gender and the legal profession's pipeline to power, as well as understanding why equality in this domain has yet to be achieved. The legal profession's power pipeline, as we conceive of it, builds on the wellestablished pipeline metaphor, which refers to the process by which women enter politics or the professions. The traditional conception of the pipeline is largely

36. Sally J. Kenney, Critical Perspectives on Gender \& Judging, 6 POL. \& GENDER 433, 434 (2010) (discussing how the study of gender and courts are at the margin "within the discipline and the subfields of both women and politics and law and courts").

37. Elliot E. Slotnick \& Jennifer A. Segal, Television News and the Supreme Court: All the NEWS THAT'S FIT TO AIR? 2 (1998).

38. See Richard Davis, Supreme Court Nominations and the News Media, 57 ALB. L. REv. 1061, $1061-$ 65 (1994) (exploring the new roles that media, interest groups, and public opinion play in relation to the Supreme Court nomination process).

39. Id. at 1065 ("The process also has been ratcheted up for the press as well. Supreme Court nominations are major news stories designed to capture public interest for several weeks or months. Public interest soars when the nominee is controversial.").

40. Id. at 1077 .

41. See, e.g., Levon Chorbajian \& Larry Beeferman, Selling Supreme Court Nominees: The Case of Ruth Bader Ginsburg, CRITICAL SOC., Oct. 1997, at 3, 4 (arguing that "the media presentation of Justice Ginsburg was a manufactured one largely consistent with the interests of corporate and government elites").

42. Davis, supra note 38, at 1072, 1077 ("Another new force, then, is the media itself, not just as a vehicle for others but as an independent influence. The news media do not serve merely as a filter for the views of other actors in the process. The organizational and professional imperatives which govern the news media shape news gathering and reporting."); see also Bybee, supra note 24, at 153 ("The newspaper coverage of the Kagan confirmation process explicitly raised this prospect of a significantly delegitimized judiciary. After Kagan was confirmed by the Senate, Curt Levey of the Committee for Justice, a group that opposed confirmation, argued that political perceptions would continue to haunt Justice Kagan on the bench."). 
numerical, suggesting that a sufficient "supply" of women will eventually result in gender parity.

Our power pipeline theory suggests that it takes far more than numerical representation to shift the course of gender representation. It is not enough that women simply be present in the pipeline or occupy a specific numerical percentage of a given profession. It also matters how women who have advanced in the pipeline are perceived, which includes how they are depicted in the media. We theorize that gender stereotyping and bias levied against women who have successfully navigated the power pipeline systemically undermines the efforts of others, explaining, at least in part, the disparate numbers in positions of power notwithstanding an equal number of women graduating from law school and entering the profession. Our Media Study lays an important foundation for evaluating this theory by documenting in a comprehensive, methodical way the gendered treatment of Supreme Court nominees by the media.

\section{Women's Advancement in the Legal Profession}

Scholars have theorized, researched, and written about the inequalities facing women in the profession for many years. A comprehensive body of literature has evolved about issues of formal equality or the obvious, explicit barriers that stood in the way of women's full participation in law. Among the most obvious barriers were the outright refusals to admit women to law school or to the practice of law. Myra Bradwell famously challenged the State of Illinois when it refused to admit her to the bar. ${ }^{43}$ When O'Connor sought employment after law school, she was only offered a secretarial job at a law firm. ${ }^{44}$ Harvard Law School's doors remained closed to women until $1950,{ }^{45}$ and Washington and Lee was the last law school to admit women in 1972. ${ }^{46}$ And, of course, not until 1981 did a woman finally sit on the Supreme Court. ${ }^{47}$

After eradication of these formal barriers, it was widely believed that women's advancement in the profession was just a matter of time. ${ }^{48}$ As an illustration, a news article appearing in the New York Times on the same day that Rehnquist and Powell were nominated to the Court lamented the small talent pool of women from which the

43. Bradwell v. Illinois, 83 U.S. 130 (1873), aff'g In re Bradwell, 55 Ill, 535 (1869). As historian Joan Hoff observes, the Bradwell decision was significant for two major reasons:

In the first place, it dealt with the extent to which the individual states could abridge the privileges and immunities of local citizens, including women. Secondly, since Bradwell also addressed the question of the right of women to practice as lawyers, it indicated the degree of willingness of the legal profession and judiciary to open their ranks to women.

JOAN HOFF, LAW, GENDER \& INJUSTICE: A LEGAL HISTORY OF U.S. WOMEN 161 (1991).

44. Biskupic, supra note 20 , at 28.

45. Law School Will Accept Women Students in Fall, THE HARVARD CRIMSON, Oct. 10, 1949, http://www.thecrimson.com/article/1949/10/10/law-school-will-accept-women-students.

46. Cynthia Fuchs Erstein, WOMEn In LAW 50 (2d ed. 1993).

47. The federal judiciary first opened to women in 1934 when President Roosevelt appointed Florence Allen to the Sixth Circuit. Ruth Bader Ginsburg \& Laura W. Brill, Women in the Federal Judiciary: Three Way Pavers and the Exhilarating Change President Carter Wrought, 64 FORDHAM L. REV. 281, 283 (1995).

48. Hilary Sommerlad calls this the "trickle up" theory, meaning that "[t]he absence of women at the top of the legal profession in general has been explained as simply due to their relatively recent participation in large numbers; top jobs will be attained in time." Sommerlad, supra note 26 , at 34 . 
President had to choose his nominees. The reporter predicted that the future would surely yield more women in the legal pipeline and thus, "the pool may contain hundreds rather than merely dozens of women because the number of women entering the legal profession and the number who appear headed for influential positions within it have started to grow very rapidly." 49 The initial focus for the women's movement addressed "quotas, refusals to hire women ... and gaining entry for women on the same terms as men." 50 This emphasis did not, however, achieve the desired "effect of affording women equal status and participation in the profession." 51

\section{a. The Pipeline Myth}

The reporter's optimistic prediction in 1971 about the legal pipeline's potential for women proved wrong. Over forty years later, proportionality in the pipeline remains unachieved. Unfortunately, "[t]he assumption that the flow of women through the career pipeline would naturally lead to proportionate representation of women was not realized." 52 Without more than a cursory look, however, some may fail to see that a problem persists. After all, women are present in almost all facets of the law, and occupy positions of leadership as law firm partners, law school deans, and Justices on the Supreme Court. The public face (and marketing brochures/websites) of law firms may include women and minority attorneys, and suggests a balanced workforce. Almost every large law firm today has a diversity initiative devoted to addressing equality for women and minorities in the firm. ${ }^{53}$ Yet the statistics document another story, one that is borne out in media coverage of powerful female attorneys.

In politics, the pipeline problem has been similarly documented. ${ }^{54}$ For example, as political scientists Jennifer Lawless and Richard Fox describe it, "[t]he basic implication of the 'pipeline' explanation is that as more and more women come to occupy the careers that are most likely to lead to political candidacies, we can assume that more and more women will run for office, contest open seats, and face no discrimination at the polls." 55 As in other contexts, this pipeline theory has not been realized: "If change continued at the present rate, it would take more than 300 years before men and women would be represented equally in Congress." 56 Although women have certainly made progress over the preceding years in gaining a more significant

49. Eileen Shanahan, President Bypasses Women for Court; Talent Pool Small, N.Y. Times, Oct. 21, 1971 , at 1 .

50. Cynthia Grant Bowman, Women and the Legal Profession, in FEMINIST JURISPRUDENCE, WOMEN AND THE LAW: CRITICAL ESSAYS, RESEARCH AGENDA, AND BIBLIOGRAPHY 625, 639 (Betty Taylor et al. eds., 1999).

51. Id.

52. ABA Comm'n on Women in the Profession, fair Measure: Toward Effective Attorney EVAluations 16 (2d ed. 2008) [hereinafter FAiR MEasure].

53. NAWL 2010 NATIONAL SURVEY, supra note 3, at 5. As this report suggests, however, the effectiveness or impact of such initiatives has not been studied or evaluated. Id.

54. See, e.g., Carroll, supra note 13, at 444-45 (discussing the "leveling off" of the number of women in state government).

55. JENNIFER L. LAWLESS \& RICHARD L. FoX, IT TAKES A CANDIDATE: WHY WOMEN DON'T RUN FOR OFFICE 26 (2005).

56. Karin Klenke, Women and Leadership: A Contextual Perspective 17 (1996). 
presence in state politics, "the leveling off of women's numbers among statewide elective officials and state legislators in recent years is a puzzling, and for many a troubling, development." $\$ 57$

Other scholars have looked at the pipeline in the academy. ${ }^{58} \mathrm{~A}$ recent study conducted on women in academia reveals " $[t]$ his disparity in numbers between men and women is both striking and extremely troubling, since-as the aggregate data suggest - this disparity represents a problem of advancement and not an absence of candidates." 59 And some have played with the pipeline metaphor, adding descriptors like the "leaking pipeline" to capture women's exit from the process. ${ }^{60}$

\section{b. Visibility and Tokenism in the Pipeline}

In law, the pipeline may indeed be leaky, but women nonetheless enter the profession and have ascended, in limited numbers, to occupy positions of power. The three female Justices sitting on the Supreme Court today are a great illustration that power is not altogether elusive. So what exactly is the problem? Law professor and director of the Stanford Center on the Legal Profession, Deborah Rhode, describes it this way: "Women's increasing representation and visibility in the profession is taken as evidence that 'the woman problem' has been solved. A widespread assumption is that barriers have been coming down, women have been moving up, and it is only a matter of time before full equality becomes an accomplished fact."

Rhode first described the phenomenon of denying that anything is amiss as the "no problem problem" in the late 1990s. ${ }^{62}$ Legal scholar and sociologist Hilary Sommerlad offers a similar perspective. Her research demonstrates ways that the "beliefs and cultural practices" of what she terms "gendered closure" have "remained after explicit exclusion of women disappeared." ${ }^{63}$ She explains that "the profession continue[s] to be conceptualised as one practised by men," 64 but it becomes difficult to quantify or even identify the impact of this conceptualization. "One of the key problems in theorising the position of women in the profession" according to Sommerlad, "is to define the exact point at which the profession can be said to cease to

57. Carroll, supra note 13, at 444-45 ("At a minimum, the leveling off is evidence that increases over time are not inevitable; there is no invisible hand at work to insure that more women will seek and be elected to office with each subsequent election.").

58. See, e.g., Am. Political SCl. Ass'N, Women's AdVAnCement In Political Science (2004); Kristen Renwick Monroe \& William F. Chiu, Gender Equality in the Academy: The Pipeline Problem, 43 PoL. SCI. \& POL. 303 (2010).

59. Monroe \& Chiu, supra note 58 , at 306.

60. See, e.g., Deborah L. Rhode, The Difference "Difference" Makes, in THE DIFFERENCE "Difference" MaKes: Women and Leadership 7 (Deborah L. Rhode ed., 2003) [hereinafter THE DIFFERENCE "DIFFERENCE" MAKES] ("In short, the pipeline leaks, and if we wait for time to correct the problem, we will be waiting a very long time.").

61. Deborah L. Rhode, Gender and the Profession: The No-Problem Problem, 30 Hofstra L. Rev. 1001,1001 (2002).

62. Deborah L. Rhode, Speaking of Sex: The Denial of Gender InEQuality I -2 (1997).

63. Sommerlad, supra note 26 , at 31 .

64. Id. 
be gendered, and how this 'gender-neutral' state will manifest itself." ${ }^{\prime \prime 65}$ Misperceptions about gender parity result as a consequence.

One explanation for these misperceptions comes from a "tendency to overestimate the proportion of a minority group present in a given population;" 66 this phenomenon has been characterized as "visibility bias." ${ }^{27}$ When women occupy positions of leadership or power within a law firm, on a court, or in another sector of the legal profession, it is not uncommon for others to perceive them as tokens. Professor of organizational leadership and head of the Leadership Development Institute International, Karin Klenke, explains that "[w]omen in leadership roles share many of the structural characteristics of tokens: they are highly visible, public individuals who attract attention with anything they do; as such, they are stand-ins for all women, symbols of how women behave and perform as leaders." ${ }^{68}$ The consequence, however, is that "[a]s tokens, women leaders are different in status from other members of their work group." 69 At the same time, as Professor Ann Bartow notes, "[w]hile women are invisible in some environments, they are viewed with significant distortion in others."70 The problem with tokenism is that it results in this distortion, where "[t]oken leaders find themselves in the organizational limelight; their actions and moves are constantly scrutinized, and they are faced with pressures that result from the application of

65. Id. at 33.

66. Rosemary Hunter, Discrimination Against Women Barristers: Evidence from a Study of Court Appearances and Briefing Practices, 12 INT'L J. LEGAL PROF. 3, 15 (2005) (citing an example from her research on discrimination against female barristers in Australia, Hunter reveals how one solicitor estimated that between twenty to thirty percent of the barristers he selected in his work were female, when the actual figure was closer to ten percent, which resulted in solicitors believing they were giving women ample opportunities); see also KANTER, supra note 26 , at 210 (discussing the attention derived from being a token in a field dominated by others, resulting in your presence being more well known).

67. Hunter, supra note 66, at 15; see also KANTER, supra note 26, at 281-84 (noting that women's success in traditionally male occupations hinges on a numerical shift in their representation beyond mere tokenism). For a more contemporary take on Kanter's work, see Elizabeth Chambliss \& Christopher Uggen, Men and Women of Elite Law Firms: Reevaluating Kanter's Legacy, 25 LAW \& SOC. INQUIRY 41 (2000). Chambliss and Uggen recently found some support for Kanter's hypothesis in limited contexts. Kanter's original research did not situate the redistributive hypothesis in the context of increased minority representation in senior leadership positions; consistent with the popular theories of that era, she was most concerned with the overall numerical composition of a workforce and not with whether minorities occupied positions of power within the organizational hierarchy. According to Chambliss and Uggen, "the chief mechanism of redistribution appears to be increased minority power." Id. at 62 (emphasis omitted). In Kanter's view, once women's aggregate percentage in the workplace increases, problems with tokenism dissipate and minorities tend to fare better; this theory is well known as Kanter's "redistributive hypothesis." $1 d$. at 43 ; see also Robin J. Ely, The Power in Demography: Women's Social Constructions of Gender Identity at Work, 38 ACAD. MGMT. J. 589, 625 (1995) (revisiting Kanter's hypothesis through quantitative and qualitative analysis of women in law firms and finding that sex-based stereotypes are more pervasive in law firms where women are absent from leadership positions); Nancy J. Reichman \& Joyce S. Sterling, Recasting the Brass Ring: Deconstructing and Reconstructing Workplace Opportunities for Women Lawyers, 29 CAP. U. L. REV. 923, 934 (2001) (suggesting that other studies have similarly found that merely adding more women to the institution will not result in redistribution unless they occupy positions of power; their location within the workplace is key).

68. KLENKE, supra note 56 , at 176.

69. Id.

70. Ann Bartow, Some Dumb Girl Syndrome: Challenging and Subverting Destructive Stereotypes of Female Attorneys, 11 WM. \& MARY J. WOMEN \& L. 221, 242 (2005). 
performance standards that are only applicable to tokens." women have reported that they must work twice as hard as their male colleagues to be considered competent."72 Additionally, "token status may also contribute to differences in leadership style by enhancing women's visibility and by lowering the likelihood that they will be members of the in-group, a combination that fosters sex stereotyping."73

\section{c. Gender Bias in the Pipeline}

In their search for explanations about women's underrepresentation in positions of leadership and power, scholars from a variety of fields like law, communication studies, political science, and sociology largely agree that stereotypes and bias play a significant role in the perpetuation of inequality. ${ }^{74}$ How these scholars theorize about and contextualize bias varies, though most agree that today's bias against women in the legal profession manifests in subtle, often implicit ways. ${ }^{75}$ As law professor Martha Chamallas has written, "[t]he new scholarship on tokenism, stereotyping, and glass ceilings suggests that updated versions of occupational and job segregation are now held in place by cognitive bias and workplace structures that replicate patterns of the past, even when those in power harbor no antipathy toward excluded groups. ${ }^{.776}$

Gender stereotypes about women's appearance, behavior, and choices are pervasive on a societal scale, and are particularly prevalent in the legal profession. Sociologist Elizabeth Gorman observes that "[g]ender stereotypes are cultural constructs, shared at the societal level, that describe what men and women are 'known' to be like." $" 7$ Stereotypes tend to strongly influence and impact how individuals

71. KLENKE, supra note 56 , at 176.

72. Id.

73. Barbara Reskin, What's the Difference? A Comment on Deborah Rhode's "The Difference 'Difference' Makes", in THE DIFFERENCE "DifFERENCE" MAKES, supra note 60, at 63 (internal quotation marks and internal punctuation omitted).

74. E.g., Deborah L. Rhode, From Platitudes to Priorities: Diversity and Gender Equity in Law Firms, 24 GEO. J. LEGAL ETHICS 1041, 1050 (2011); see also Mark D. Agars, Reconsidering the Impact of Gender Stereotypes on the Advancement of Women in Organizations, 28 PSYCHOL. WOMEN Q. 103, 106 (2004) (noting that the effect of gender stereotypes on women in the workforce is cumulative). Many additional possible reasons proliferate the literature. See, e.g., KLENKE, supra note 56, at 182-83 (discussing how informal networks like mentoring and networking within organizations operate as structural barriers to women's advancement); Rhode, supra note 60 , at 7 (identifying three major barriers to women's advancement as "traditional gender stereotypes, inadequate access to mentors and informal networks of support, and inflexible workplace structures").

75. See, e.g., FAIR MEASURE, supra note 52, at 16 ("Studies show that although explicit stereotyping ('women are not smart enough to be lawyers') has fallen sharply since the 1970s, implicit, unacknowledged bias ('mothers of young children are less committed to their jobs') has changed very little.'); see also SUSAN

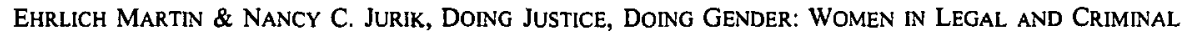
JUSTICE OCCUPATIONS 126 ( $2 \mathrm{~d}$ ed. 2007) (characterizing today's gender bias as "second generation bias" which is free from explicit exclusionary practices). Experts observe that "[g]ender bias today typically does not take the form of misogyny and does not include the explicit opinion that the law is not a suitable profession for a woman. Gender bias today is often subtler." FAIR MEASURE, supra note 52, at 16.

76. Martha Chamallas, InTRoduction to Feminist Legal Theory 186-87 (2003).

77. Elizabeth H. Gorman, Gender Stereotypes, Same-Gender Preferences, and Organizational Variation in the Hiring of Women: Evidence from Law Firms, 70 AM. SOC. REv. 702, 703 (2005). 
perceive one another, ${ }^{78}$ and are sometimes referred to as "descriptive shortcuts applied to categories of people." "79 As Professor Klenke explains, "[a]lthough stereotypes may, in fact, often be based on a grain of truth, in reality they more often conceal than they reveal." 80 Stereotypes can be further broken down into two categories: descriptive and prescriptive stereotypes. ${ }^{81}$ According to Joan Williams, law professor and director of the Center for WorkLife Law, "[a] descriptive stereotype describes how an individual is presumed to behave. ... [P]rescriptive stereotypes prescribe how women (or men, or mothers) should behave." 82 Thus, legal ethics scholar Eli Wald concludes, "[t]he existing literature correctly identifies gender stereotypes as an important factor explaining the glass ceiling effect and the underrepresentation of women lawyers in prestigious segments of the legal profession." 83 Professor Klenke suggests that the media's coverage of women in leadership positions often occurs in a "stereotypical manner." ${ }^{84}$ Indeed, our own Media Study reveals a proliferation of bias and stereotypes; ${ }^{85}$ we use the media's portrayal of women on the Supreme Court as a way to illuminate what women lawyers encounter in their individual professional lives.

Stereotypes also play into the construct of "double binds" facing women in the legal profession. Ideas about how women are supposed to act conflict with how they do act. Described originally by legal philosopher Marilyn Frye in her seminal work The Politics Of Reality ${ }^{86}$ others, like communication scholar Kathleen Hall Jamieson, have devoted significant attention to describing the "binds that tie." 87 Jamieson identifies five types of binds 88 that are used "by those with power against those without," 89 thereby interfering with women's advancement in the workforce.

78. $I$. .

79. KLENKE, supra note 56 , at 165.

80. Id.

81. Joan C. Williams, The Social Psychology of Stereotyping: Using Social Science to Litigate Gender Discrimination Cases and Defang the "Cluelessness" Defense, 7 EMP. RTS. \& EMP. POL'Y J. 401, 406 (2003).

82. Id. (emphases omitted); see also Joan C. Williams, Litigating the Glass Ceiling and the Maternal Wall: Using Stereotyping and Cognitive Bias Evidence to Prove Gender Discrimination, 7 EMP. RTS. \& EMP. POL'Y J. 287, 288 (2003) (describing how, in a case of maternal wall bias, an employer terminated an employee based on the belief that she belonged "at home with her child" (quoting Bailey v. Scott-Gallaher, Inc., 480 S.E.2d 502, 503 (Va. 1997))

83. Eli Wald, Glass Ceilings and Dead Ends: Professional ldeologies, Gender Stereotypes, and the Future of Women Lawyers at Large Law Firms, 78 FordHAM L. REV. 2245, 2274 (2010); see also id. at 227375 (explaining how, through the proliferation of three kinds of stereotypes faced by women lawyers, law firms ultimately conclude that hiring women is "not . . . worth the investment").

84. KLENKE, supra note 56 , at 118.

85. See infra Part III for a comprehensive discussion of proliferation of bias and stereotypes found in our Media Study around themes of gender, motherhood and marriage, competency, and appearance.

86. See FRYE, supra note 29 , at 3-4 (describing how the double binds catch " [w]omen . . too, by networks of forces and barriers that expose one to penalty, loss or contempt whether one works outside the home or not, is on welfare or not, bears children or not, raises children or not, marries or not, stays married or not, is heterosexual, lesbian, both or neither").

87. JAMIESON, supra note 29 , at 3.

88. Jamieson's binds include: Womb/Brain, Silence/Shame, Sameness/Difference, Femininity/Competence, and Aging/Invisibility. Id. at 15-16.

89. Id. at 5 . 
This kind of framework serves as a useful starting place for thinking about gender bias in the context of women in the legal profession, but modern gender bias is less easily categorized. Our Media Study findings demonstrate that bias leveraged against women based on motherhood, competence, and appearance infrequently exists in isolation and intersects in various and competing ways, rendering Jamieson's binary juxtapositions less workable for addressing the concerns she raised nearly two decades ago, particularly to the extent she suggests that women have moved beyond these binds. If anything, the media coverage of the most recent nominees to the Supreme Court shows that the same concerns dominate women's advancement. We believe our Media Study will facilitate the contextualization of bias against women by recognizing new complexities as we rethink Frye's and Jamieson's double binds. Two of the binds Jamieson identified figured prominently in our Media Study, and we address each briefly below.

i. Rethinking the Womb/Brain Double Bind: The Complexity of (Non)Motherhood

Stereotypes, bias, and binds based on issues of motherhood proliferate the legal workplace and impede women's advancement; their impact and consequences have been extensively addressed. For example, Martha Chamallas explains how far-reaching motherhood bias extends, even affecting "women who have never been mothers or will never be mothers." Joan Williams is widely known for her characterization of the bias and discrimination faced by women in the workplace. Specifically, she addresses this bias in relation to their roles as mothers or potential mothers, something she describes as the "maternal wall." 91 She explains that "[l]ong before most women get near the glass ceiling, they are stopped by the maternal wall: bias against women not because they are women, but because they are mothers." 92 This is significant, according to Williams, because "[b]ias against mothers stems not only from assumptions about what mothers are like, but also from assumptions about how mothers should behave. Even today, women often encounter statements indicating that mothers don't belong in the workplace." 93

90. Chamallas, supra note 76 , at 288 (discussing how the category "woman" is linked with "motherhood," regardless of one's desire to be a mother and how "the importance of the category 'mother' to feminism and feminist legal theory is unquestioned").

91. A comprehensive discussion of Williams's extensive work on the "maternal wall" and bias against women in the workplace is beyond the scope of this Article. For a discussion of Williams's work, see generally Faye J. Crosby et al., The Maternal Wall: Research and Policy Perspectives on Discrimination Against Mothers, $60 \mathrm{~J}$. SOC. ISSUES 675 (2004). For a discussion integrating family responsibility discrimination case law with the Equal Employment Opportunity Commission's 2007 issuance of enforcement guidance on caregiver discrimination, see Joan C. Williams \& Stephanie Bornstein, The Evolution of "FReD": Family Responsibilities Discrimination and Developments in the Law of Stereotyping and Implicit Bias, 59 HASTINGS L.J. 1311, 1315 (2008).

92. Williams, supra note 81 , at 404 (emphasis omitted).

93. Maternal Wall, GENDER BIAS LEARNING PROJECT, http://www.genderbiaslearning.com/stereotype_m aternalwall.html (last visited Mar. 5, 2012) ("Such statements can either be hostile ('Mothers belong at home') or benevolent, ('I assumed she didn't want the fellowship because she just had a baby')."). 
Professor Jamieson has also documented this phenomenon of bias leveraged against mothers, describing it as an ongoing womb/brain double bind experienced by women in the workforce. Originally, it was thought that "one could have either career or marriage and motherhood, but not both." 94 That bind was eventually replaced by the idea that indeed "[o]ne could have both career and family, but not at the same time." 95 In her last characterization of this dichotomy, Jamieson describes the bind's operationalization as the idea that " $[\mathrm{t}]$ hey can have both at the same time, but only at the cost of cheating one or the other." 96 Other scholars have similarly noted the dilemma. For example, Deborah Rhode notes that "[w]omen with children face additional double standards and double binds." 97 She observes that women are held to higher standards of parenting and are judged to be "insufficiently committed, either as parents or professionals." 98 Stark examples of the binds described by Williams, Jamieson, Rhode, and others are found in our Media Study. For the female nominees, motherhood (or nonmotherhood, as in the case of the three most recent female nominees to the Court) became a repeated focus in media coverage about their qualifications to the Court, as discussed further in Part III.B.1.

ii. Rethinking the Femininity/Competence Double Bind: The Complexity of Appearance as a Measure of Competence

Perceptions of women's competency related to their appearance also figured prominently in our Media Study, reminding us of another of Jamieson's double binds: femininity/competence. ${ }^{99}$ Under her conception, women are forced to choose between being perceived as feminine or being perceived as competent, or, in other words, women must forsake femininity should they want to be deemed competent. ${ }^{100}$ As commentators have observed, "[w]omen often face a form of glass ceiling bias that is a 'Catch 22': either they are penalized for not being competent enough or for being too competent." 01 Equally problematic, women are frequently "assumed to be less competent than men." 102 As a result, "women often have to "jump through more hoops' to prove their ability to do good work due to background expectations that they will perform worse." 103 Joan Williams characterizes this kind of bias related to the perception of women's competence in the workforce as "prove it again," which refers

\footnotetext{
94. JAMIESON, supra note 29, at 54.

95. Id.

96. Id.

97. Rhode, supra note 60 , at 10.

98. Id.

99. For a full discussion of the competency double bind, see JAMIESON, supra note 29 , at $120-45$.

100. Id.

101. Mona Harrington et al., Advancing Women in the Profession: action Plans for WOMEN'S BAR ASSOCIATIONS 8 (2007).

102. See JAMIESON, supra note 29 , at $122-25$ (citing social scientific evidence, personal anecdotes, media examples, and other research to support the claim); Rhode, supra note 60 , at 8 ("[F]emale leaders ... often lack the presumption of competence accorded to their male counterparts.").

103. Williams, supra note 81 , at 413 (footnote omitted)
} 
to the "phenomenon ... where men are judge[d] on their potential, whereas women are judged on their accomplishments." 104

The femininity/competence bind is especially acute in the context of appearance bias. Although appearance bias impacts men and women, the consequences for women are particularly harsh. Law professor Maureen Howard attributes this to a complexity that, as a practical matter, plays out differently for women. ${ }^{105}$ She cites a number of reasons for this: "the delayed entrance of women into the workforce in general, and trial work in particular; gender bias and stereotypes; issues surrounding female sexuality in the workplace; and the differential societal emphasis on and breadth of gender-specific clothing choices." 106 Other scholars, in contrast, recognize the validity of appearance as a workplace qualification. ${ }^{107}$

Our project aims, in part, to shed an empirical light on the "beauty bias" identified by Professor Rhode ${ }^{108}$ and the focus on women's appearance identified by others. Rhode has written extensively about what she terms "the beauty bias," a concern that is perhaps most problematic because of "our failure to recognize that it is a significant problem and one to which law and public policy should respond." 109 In comparing appearance bias "with other inequities that the contemporary women's movement has targeted" she finds "strikingly little improvement" here. ${ }^{110}$ She challenges her readers to consider "appearance not only as an aesthetic issue, but as a legal and political one as well."111

The negative political implications of appearance bias also must be acknowledged. Sociologists Susan Ehrlich Martin and Nancy Jurik offer the example of "a judge allow[ing] the opposing attorney to label a woman attorney's appearance a 'distraction,' [thus] signal[ing] to others that it is acceptable to use a woman's looks as the basis for objecting against other woman attorneys." 12 Here, the implications for the individual attorney (and her client) almost pale in comparison to the broader consequences for women attorneys overall. Studies reveal that women face far more frequent compliments on their appearance than on the substance of their legal work, in contrast to male attorneys who receive no appearance-based comments and are

104. Id. at 417 .

105. Maureen A. Howard, Beyond a Reasonable Doubt: One Size Does Not Fit All When it Comes to Courtroom Attire, 45 GoNZ. L. REV. 209, 211 (2010).

106. Id. (footnotes omitted).

107. See, e.g., Katharine T. Bartlett, Only Girls Wear Barrettes: Dress and Appearance Standards, Community Norms, and Workplace Equality, 92 MICH. L. REV. 2541, 2580 (1994) ("Although courts tend to treat dress and appearance matters as legally insignificant, all the available management literature supports the view that dress and appearance matter a great deal in the workplace, as they do in other social contexts, and it is clear that on both an individual level and with respect to women as a whole, dress and appearance have important, albeit complicated, autonomy and equality implications." (footnote omitted)); Catherine Thérèse Clarke, Missed Manners in Courtroom Decorum, 50 MD. L. REV. 945, 1001 (1991) (noting that common sense indicates judges and jurors will pay attention to trial participants and their appearance).

108. Deborah L. Rhode, The Beauty Bias: The injustice of Appearance in Life and LaW 2 (2010).

109. Id. at 2.

110. Id.

111. Id. at 161.

112. MARTIN \& JURIK, supra note 75 , at 127. 
complimented almost exclusively on their substantive legal contributions. ${ }^{113}$ As Professor Rhode notes, this "[o]veremphasis of their appearance deflects attention from their performance and reinforces sex-based double standards." 114

Significantly, our preliminary findings reveal a greater emphasis on the appearance of female nominees than their male counterparts, though both female and male nominees receive a questionable amount of attention. Although one might dismiss the greater discussion of appearance as trivial (after all, the nominees ultimately do not receive confirmation based upon an evaluation of their appearance, at least not explicitly), the media's emphasis on appearance matters. Indeed, Professor Davis suggests that "the nominee's self presentation [has] become too important in the process." 115 He points to "Robert Bork's scraggly beard," asking whether the "beard help[ed] portray him as 'outside the mainstream' of the legal community."116 "These questions," argues Davis, "should become the subject of increased scholarly research into the process of nominating Justices in a media age," a call heeded by our Media Study. ${ }^{17}$

\section{Gender and the Media}

Our project is not primarily concerned about the extent to which the media actually influences the public's perception of the nomination process, but the media's well-established role in disseminating information and shaping public perception is notable. ${ }^{118}$ In her work on gender-based medial portrayals, Deborah Rhode has noted that "[f]or any social movement, the media play a crucial role in shaping public consciousness and public policy." "19 Similarly, Kathleen Hall Jamieson "suggest[s] that reporters and editors" not only "reflect[] widely held and hence largely unquestioned assumptions" in society, but also that "widespread journalistic practices can accelerate or retard forces at work elsewhere in society." 20 Speaking specifically to the "sources of the public's perception of the courts," Professor Bybee adds that "[f]or many Americans, the media seems to play a critical role."121

In their study of television news and the Supreme Court, political scientists Elliot Slotnick and Jennifer Segal explain that "a long history of empirical research . . . suggests that the media play[s] a very active and influential role in affecting what we

113. Id. at 145 .

114. RHODE, supra note 108 , at 9.

115. Davis, supra note 38 , at 1078.

116. Id.

117. Id. at 1079 .

118. Feminists in particular find studies of the media revealing. See JAMIESON, supra note 29, at 164-83 (discussing ways that media conveys double-binds on women); Deborah L. Rhode, Media Images, Feminist Issues, 20 SIGNS 685, 685 (1995) (analyzing how the media portrayed "feminism, feminists, and genderrelated issues" in the latter half of the twentieth century).

119. Rhode, supra note 118 , at 685 .

120. JAMIESON, supra note 29 , at 166.

121. Keith J. Bybee, The Two Faces of Judicial Power, in BenCH Press: The Collision of THE COURTS, POLITICS, AND THE MEDIA 3 (Keith J. Bybee ed., 2007) [hereinafter BENCH PRESS]. 
know and what we think is important in politics." 122 The media's influence comes with responsibility, because "those who operate within the media industry have the discretion to cover some subjects and not others, and because they have control over how the information is presented to the American public." ${ }^{123}$ Members of the media have choices in what becomes news and how that news is covered. And "[i]n the choices that are made, the media have the potential for enormous power over what we know, understand, and think about our political world."124

There are two aspects of this discourse on media and gender that relate directly to our Media Study and warrant brief mention here. One is the gendered nature of the institution of journalism, specifically the reporting process. A second is the extent to which media reflects culture and social understanding.

Gendered dimensions of journalism and media exist both in the substantive content of what is being produced, and the production process itself. The field of print journalism is one dominated by male executives and reporters. Although "it is difficult to obtain industry-wide statistics" on the presence of women executives in the media, a White House Project report indicates that at least fifteen of the nation's leading media companies do not have a female CEO or board chair and that women are highly underrepresented on their boards of directors. ${ }^{125}$ As for print media on the ground, the numbers are not any better, with women comprising only thirty-seven percent of fulltime staff positions at daily newspapers, ${ }^{126}$ ten percent of executive vice-presidents and general managers at large newspapers, ${ }^{127}$ and twenty-nine percent of all executives. ${ }^{128}$ The OpEd Project tallies the gender breakdown of opinion bylines in major newspapers; for the period December 24-31, 2010, in the New York Times, eighteen of the total opinion pieces were written by women, compared to eighty-two written by men. ${ }^{129}$ The Washington Post statistics almost mirrored the Times, with sixteen of the opinion bylines attributed to women, and eighty-four to men. ${ }^{130}$ Our Media Study

122. SLOTNICK \& SEGAL, supra note 37, at 6; see also FALK, supra note 34 , at 28 (noting that in the context of presidential elections, "[ $[$ ] he media not only tell us who our national candidates are, but they are also instrumental in creating our common conceptions of them"); Virginia Sapiro \& Joe Soss, Spectacular Politics, Dramatic Interpretations: Multiple Meanings in the Thomas/Hill Hearings, 16 POL. COMM. 285, 308 (1999) (conducting study of mass media during the hearings involving then-nominee Clarence Thomas and the Anita Hill sexual harassment allegations, and concluding that "[p]ublic responses to the Thomas/Hill hearings drew on a diverse set of overlapping narratives and symbols," which provided multiple influences on viewers and readers depending upon the source).

123. SLOTNICK \& SEGAL, supra note 37 , at 6 .

124. Id. The way media portrayal influences public perceptions about Supreme Court nominees is beyond the scope of our Media Study at this time; but is an important line of analysis deserving of future research.

125. THE WhITE HOUSE PROJECT, supra note 26, at 49.

126. U.S. Newsroom Employment Declines, AM. SOC'Y OF NEwS EDITORS (Apr. 16, 2009, 12:57 PM), http://asne.org/article_view/smid/370/articleid/12/reftab/101.aspx. This data is from a 2009 "newsroom employment census" with a response rate of " 66.26 percent of all U.S. dail[y]" newspapers. Id.

127. MARY ARNOLD \& MARY NESBIT, WOMEN IN MEDIa 2006: Finding the LEAdER IN YOU 28 (2006). This data is from a "gender count of managers at 137 newspapers with circulation over 85,000." Id. at 27.

128. Id. at $27-28$.

129. THE OPED PROJECT, http://www.theopedproject.org (last visited Mar. 5, 2012).

130. Id. 
similarly found a disproportionate number of articles written by male reporters as documented by our fifth preliminary finding, discussed below. ${ }^{131}$

Media also creates and reflects popular culture. As law professor Stacy Caplow notes, "[a]n examination of the depiction of law and lawyers in popular media is most useful as a measurement of the general public perception of the law and the legal profession." 132 For example, she explains that "[l]ooking at images of law and lawyers in popular culture permits us to view a version of the real social impact of legal ideas as seen through the eyes of a creative interpreter and as processed by a lay audience."133 Furthermore, she suggests that "[e]xamining images of women lawyers thus permits us to question the status that women seem to have attained in the legal profession, and the personal, moral, or emotional adjustments they have been required to make in order to participate in that world, as conceived on film." 134 From these images "[w]e can also ask how the public is likely to perceive women lawyers as a result of these images."135 This is equally true of journalism as it is of film, literature, and the arts. ${ }^{136}$ Consequently, mainstream news reporting "bears some responsibility for creating the public's understanding of the law since many people derive all of their information about the meaning of legal events through the lens of popular media." 137 Other scholars like Kathleen Hall Jamieson go even a step further: "The press, in other words, perpetuates the binds that tie." 138

Because news media purports to convey facts rather than fiction, we submit that the news industry bears unique responsibilities. Other scholars agree. For example, Rhode suggests that media play a role in counteracting the beauty bias identified in her own research. She recommends that the media portray "more diverse and healthy cultural ideals" and cover more "appearance discrimination" along with "more responsible treatment of weight-related issues."139 Similarly, one goal of our Media

131. See infra Part III.A for a discussion of the results of our Media Study.

132. Stacy Caplow, Still in the Dark: Disappointing Images of Women Lawyers in the Movies, 20 WOMEN'S RTS. L. REP. 55, 58 (1999).

133. Id.

134. $I d$.

135. Id.; see also Anna M. Archer, From Legally Blonde to Miss Congeniality: The Femininity Conundrum, 13 CARDOzo J.L. \& GENDER 1, 21 (2006) (concluding that "[t]he popular media plays a role in the development" of gender-based role expectations by reinforcing "the stereotypical viewpoints already intact in society").

136. For further discussion on the portrayal of women lawyers in other areas of media, such as television and film, see Archer, supra note 135, at 1 (suggesting that "popular movies ... illustrate how the influence of . . .gender stereotypes ... serves as a blockade along the route to gender equality"); Diane Klein, Ally McBeal and Her Sisters: A Quantitative and Qualitative Analysis of Representations of Women Lawyers on PrimeTime Television, 18 LOY. L.A. ENT. L. REV. 259, 260 (1998) (finding "that substantial biases, in the form of representational inaccuracies, persist in prime-time television's depiction of women lawyers"). See also Victoria Alexeeva, Comment, Images of Women Lawyers: Over-Representation of Their Femininity in Media, 4 CARDozo WOMEN's L.J. 361, 376 (2003) (arguing that popular television shows like "Ally McBeal" "portray[] women lawyers through a male standard for women").

137. Caplow, supra note 132 , at 58.

138. JAMIESON, supra note 29, at 165.

139. RHODE, supra note 108 , at 151. 
Study is to suggest that consideration be given to a more balanced portrayal of women lawyers.

\section{Gender and Judging}

Our Media Study operates from the premise that we need more women in the judiciary. ${ }^{140}$ In making such an assertion, however, we neither assume that all female judges adjudicate from a feminist standpoint, nor base our research upon this premise. Legal scholar Theresa M. Beiner identifies numerous categories around which scholars typically gravitate in justifying their support of diversity in the federal judiciary. ${ }^{141}$ Beiner articulates: "In the end, there are many good reasons to diversify the federal bench. Whether the argument be based on issues of fairness, legitimacy, providing role models, or incorporating a variety of American experiences and perspectives into judicial decision making, the case for a diverse judiciary is strong." 142

The scholarship surrounding the influence of female judges has largely "considered how judges vote differently from or similar to their male colleagues or whether they have pursued a common women's judicial identity." 143 The literature is mixed; scholars argue both for and against the proposition that gender makes a difference. ${ }^{144} \mathrm{We}$ are not concerned at this juncture, however, with the ideological perspectives of Supreme Court nominees, other than to consider how the media might portray such perspectives. That said, a rich literature exists exploring the impact of gender on judging. ${ }^{145}$ Although a comprehensive review of this literature is beyond the

140. See supra note 31 and accompanying text for a discussion of varying viewpoints addressing the idea that more women are needed in the judiciary.

141. Theresa M. Beiner, White Male Heterosexist Norms in the Confirmation Process, WOMEN's RTS. L. REP. (forthcoming 2012) (manuscript at 15-18), available at http://ssrn.com/abstract=1706164 (identifying categories of opinion on why diversity on the bench matters, like symbolic or functional representation, substantive representation, and providing role models for those individuals who have not previously been represented on the bench).

142. $1 d$. at 20.

143. Karen O'Connor \& Alixandra B. Yanus, Judging Alone: Reflections on the Importance of Women on the Court, 6 POL. \& GeNDER 441, 446 (2010).

144. See, e.g., Paul M. Collins et al., Gender, Critical Mass, and Judicial Decision Making, 32 L. \& PoL'Y 260, 261, 263 (2010) (reflecting that "[c]onsidered collectively, the result of research subjecting gender effects to empirical scrutiny in the judicial arena has been decidedly mixed," leading to a failure to "uncover systematic differences between male and female jurists"); Kenney, supra note 36, at 436 (noting that political scientists have found that gender does not effect judicial decision making, with the occasional exception of some sex discrimination and divorce cases); Deborah Rhode, In a "Different" Voice: What Does the Research About How Gender Influences Judging Actually Say?, SLATE (June 10, 2009, 4:20 PM), http://www.slate.com/id/2220220 (discussing the "cottage industry of empirical work [that] has tried to disentangle the influence of gender on judging" and observing that the "[r]esults vary" on whether gender makes a difference).

145. See, e.g., Dixon, supra note 31 , at $304 \&$ n.37 (providing a list of scholars who suggest that "Justices O'Connor and Ginsburg have adopted a distinctively 'feminine' jurisprudential approach simply by reason of being female"); Anita F. Hill, What Difference Will Women Judges Make? Looking Once More at the "Woman Question", in WOMEN AND LEADERSHIP, supra note 30, at 185-86 (concluding that female judges "make a difference" on the bench because the contribution of their alternative perspective "reaffirms the promise of equality under the law" and may "influence ... the overall direction the law takes"). 
scope of this Article, we highlight certain aspects as part of the backdrop for understanding the outcomes of our Media Study.

A notable study conducted by law scholars Stephen J. Choi, Mitu Gulati, Mirya Holman, and Eric A. Posner tested the hypothesis that female judges are worse (or, as Sotomayor claimed, better) than men. ${ }^{146}$ Distinguishing their research from the prior literature that asks whether "female judges are likely to bring a distinctive perspective to bear [on their cases]," their study instead focuses on "the relationship between the gender of judges and judicial quality," and tests "whether gender has a significant effect on judicial performance." 147 After examining all the state high court judges from 1998 to 2000 using three measures of "judicial output"- "opinion production, outside state citations, and co-partisan disagreements"- the study failed to find significant evidence that gender effects the quality of judicial performance, ${ }^{148}$ though it should be noted that some dispute their results. ${ }^{149}$

Other empirical work, however, has found a "link between a judge's gender and the likelihood of her voting for the plaintiff in sex discrimination and sexual harassment cases under Title VII."150 For example, Christina L. Boyd, Lee Epstein, and Andrew D. Martin are the authors of a highly regarded study, Untangling the Causal Effects of Sex on Judging. ${ }^{151}$ Their work explores "the role of sex in judging by addressing two questions of long-standing interest to political scientists: whether and in what ways male and female judges decide cases distinctly- 'individual effects'-and whether and in what ways serving with a female judge causes males to behave differently-'panel effects." "152 Their study, based on an evaluation of the impact of gender in an unprecedented thirteen areas of law, found that "the presence of women in the federal appellate judiciary rarely has an appreciable empirical effect on judicial outcomes. Rarely, though, is not never." 153 Finally, there is a proliferation of research and empirical studies that consider the impact of gender on judicial decision making in the context of specific issues, such as sexual orientation, child custody, and criminal sentencing. ${ }^{154}$

146. Stephen J. Choi et al., Judging Women, 8 J. EMPIRICAL LEGAL STUd. 504, 504 (2011).

147. Id. at 505 .

148. Id. at 504. But see Royce de R. Barondes, Federal District Judge Gender and Reversals 19 (July 15, 2010) (unpublished manuscript), available at http://papers.ssm.com/sol3/papers.cfm?abstract_id $=1640876$ (arguing that the results in Choi et al., supra note 146, are "not informative" because the authors do not consider that a relationship may already exist between gender and their selected measures of judicial performance, and therefore choosing a different methodology).

149. See Barondes, supra note 148 , at 19.

150. Dixon, supra note 31 , at 312 . For a summary of empirical work documenting a correlation between the gender of a judge and the outcome in sex discrimination and sexual harassment cases, see $i d$. at 311-12. (2010).

151. Christina L. Boyd et al., Untangling the Causal Effects of Sex on Judging, 54 AM. J. POL. SCI. 389

152. Id. at 389 .

153. Id. at 406 .

154. See, e.g., Elaine Martin \& Barry Pyle, State High Courts and Divorce: The Impact of Judicial Gender, 36 U. TOL. L. REV. 923, 940-41 (2005) (concluding that female state supreme court justices are more likely than their male colleagues to vote in "support of the female litigant's position in cases of divorce, child custody, child support, spousal maintenance, and property settlement"); Darrell Steffensmeier \& Chris Hebert, Women and Men Policymakers: Does the Judge's Gender Affect the Sentencing of Criminal Defendants?, 77 


\section{B. The Unexplored Intersection of Gender, Media, and the Supreme Court}

Research on gender, media, and government largely surrounds the electorate and rarely includes the courts. For example, political science studies often focus on the role of gender in state campaigns (gubernatorial and legislative candidates) and federal presidential and congressional races. ${ }^{155}$ In a similar vein, Professor Erika Falk, a noted communications scholar, has published a comprehensive study documenting the gender-based media bias in the campaigns of women for president. ${ }^{156}$

The judiciary, and especially the Supreme Court, remains a relatively untouched site for exploration, empirical or otherwise, of gender and media related issues, an omission that scholars in the field acknowledge. As Professor Sally Kenney comments on this absence, "[t] $]$ he flurry of attention over such rare events as the nomination of a woman to the U.S. Supreme Court or a conference on the 200th anniversary of women and the constitution (1988 in Atlanta) punctuates the silence of the routine absence of a gender analysis of our third branch of government." 157 That the courts are relatively unexplored in this context, however, does not mean that they are not deserving of attention. Professor Kenney suggests that " $[t]$ reating the study of law and courts as a subfield of American politics makes even less sense than ever."158 And Professor Linda Greenhouse notes, going a step further, "press coverage of the courts is a subject at least as worthy of public concern and scholarly attention as press coverage of politics, perhaps even more so."159

Among those scholars who analyze the Supreme Court nomination process, ${ }^{160}$ few focus on the media's portrayal of the Justices themselves as compared to the decisions rendered by the Court. ${ }^{161}$ As political scientist and media studies scholar

SOC. FORCES 1163, 1186 (1999) (concluding that female judges are "somewhat more likely to incarcerate defendants and impose somewhat longer prison sentences than [male] judges"); Fred $\mathbf{O}$. Smith, Jr., Note, Gendered Justice: Do Male and Female Judges Rule Differently on Questions of Gay Rights?, 57 STAN. L. REV. 2087, 2123 (2005) (concluding that female judges are more likely than male judges to rule that a law violates gay rights). For an innovative analysis of scholars who look at gender differences in judging, see Sally J. Kenney, Thinking About Gender and Judging, 15 INT' L J. Legal Prof. 87, 105-07 (2008).

155. E.g., LAWLESS \& FOX, supra note 55, at 16-36 (examining the effect of gender bias on the emergence of viable female candidates and the difference between male and female decisions to run for office). Jennifer Lawless and Richard Fox, in attempting to answer the question of why women choose not to run for office, empirically investigated the intersections of gender and candidate ambition and found that "[a] the individual level .. . gender expectations and stereotypes persist and can affect the evaluations and experiences of women candidates and officeholders." Id. at 24 .

156. See generally FALK, supra note 34 .

157. Kenney, supra note 36 , at 434 .

158. Id. at 435 .

159. Linda Greenhouse, Telling the Court's Story: Justice and Journalism at the Supreme Court, 105 YALE L.J. 1537, 1538 (1996). Professor Greenhouse's article explores obstacles, created and perpetuated by the powerful institutions of journalism and the Supreme Court, that inhibit important public understanding of the Court. $I d$. at 1539.

160. For two examples of interesting work on Supreme Court nominees that omit discussion of the media's role in the nomination process, see James L. Gibson \& Gregory A. Caldeira, Confirmation Politics and the Legitimacy of the U.S. Supreme Court: Institutional Loyalty, Positivity Bias, and the Alito Nomination, 53 AM. J. Pol. SCI. 139 (2009); Mark Silverstein \& William Haltom, You Can't Always Get What You Want: Reflections on the Ginsburg and Breyer Nominations, 12 J.L. \& PoL. 459 (1996).

161. SLOTNICK \& SEGAL, supra note 37 , at 2. 
Richard Davis, author of "one of the few scholarly studies on this subject"162 notes, "[t]he Supreme Court usually has been excluded from a discussion of political institutions and their relationship with the press," with the exception of a "small number of empirical studies .... [that] focus[] on the amount and nature of news coverage of the Court [and its decisions]" and essentially criticize the quantity of coverage that occurs. ${ }^{163}$ Although some scholars have begun to examine media coverage of Supreme Court nominees, to our knowledge none employ empirical analysis to assess the role of gender in the quantity and quality of media coverage received by Supreme Court nominees. For example, communication science scholars have used studies of media coverage during the nomination periods to analyze differences between press and blog coverage in the context of new mediated deliberation ${ }^{164}$ or the relationship between politics, media, and blogs. ${ }^{165}$ Similarly, legal and political science scholar Keith Bybee recently published an essay on the media's depiction of Kagan's nomination. ${ }^{166}$

Some scholars focus specifically on the nomination/confirmation process, including law professors Lori Ringhand and Paul Collins, who conducted an empirical study of Senate Judiciary Committee hearings for nominees to the Court from 1939 to 2009. ${ }^{167}$ They found evidence "that female and minority nominees are differently treated than more traditional white male nominees." 168 As just one example, they noted that "senators pressed female and minority nominees substantially more often on issues of judicial philosophy and banking and finance."169 They also discovered that "senators engaged in far less comments involving hearing administration and chatter for female and minority nominees, indicating that senators interrogated female and minority nominees on more substantive issues than white male nominees." 170 They assert that their study will assist "scholars interested in exploring causal mechanisms explaining

162. Greenhouse, supra note 159 , at 1559.

163. Richard Davis, Decisions AND IMAges: The Supreme CourT AND the Press, at xi (1994) (“All [studies about the media's depiction of the Court] have concluded that news coverage of the Court is superficial and spotty."). For a different perspective on this issue, see Greenhouse, supra note 159, at 1559 ("In the view of . . . political scientist Richard Davis, the press is a public relations tool for the Court specifically for the task of reinforcing deference toward its decisions. That is not the Court and not the press corps I have observed for these last eighteen years. Rather, I see a Court that is quite blithely oblivious to the needs of those who convey its work to the outside world, and a press corps that is often groping along in the dark, trying to make sense out of the shadows on the cave wall." (footnote omitted) (internal quotation marks omitted)). See also Michael Comiskey, Not Guilty: The News Media in the Supreme Court Confirmation Process, 15 J.L. \& POL. 1, 1 (1999) (concluding that "media coverage of recent confirmations has benefited both the public and the nominees").

164. E.g., Michael Xenos, New Mediated Deliberation: Blog and Press Coverage of the Alito Nomination, 13 J. COMPUTER-MEDIATED COMM. 485 (2008).

165. E.g., Taylor Ansley \& Patrick Sellers, Press Independence and Blogs in the Alito Nomination Debate, 36 CONGRESS \& THE PRESIDENCY 297 (2009).

166. Bybee, supra note 24.

167. Lori A. Ringhand \& Paul M. Collins, Jr., May it Please the Senate: An Empirical Analysis of the Senate Judiciary Committee Hearings of Supreme Court Nominees, 1939-2009, 60 AM. U. L. REV. 589 (2011).

168. Id. at 633 .

169. Id.

170. Id. 
the connection between public opinion and the evolution of constitutional law" because the data "provide useful information regarding how senators and nominees use the conformation process to validate, refute, or debate constitutional change over time."171

Our project, in contrast, sits at the unique intersection of law, gender, political science, and mass media. We recognize that some may find our merger of these fields controversial, especially because we are using this convergence to analyze the place of women lawyers in the profession. ${ }^{172}$ Professor Ann Bartow notes that "[w]riting about women lawyers is a somewhat nerve wracking proposition" because feminist academic writers can be particularly hard on each other. ${ }^{173}$ She also observes that "[f]eminism does not have a universally recognized governing body, and 'feminism' is not a brand or trademark with a fixed social or commercial meaning. Investigations into what feminism is, or should be, have fueled debates and created rich bodies of varied scholarship."174

We acknowledge that there are some feminist scholars who may take issue with our approach. For example, legal scholar Rosalind Dixon is critical of various empirical studies on gender and judging that suggest a correlation between an increase in female judges and an increase in results that will support feminist values. ${ }^{175}$ She contends that merely adding more women will not necessarily result in more judges who are "sympathetic to pro-feminist views." 176 There are some compelling reasons to agree with Dixon's thesis. We concur, for example, with Dixon's observation that men can advance a feminist agenda, and that, conversely, women might compromise that same agenda. ${ }^{177} \mathrm{~A}$ study by political science scholars Maya Sen and Adam Glynn is telling on this point, revealing that one's life experience (i.e., raising a daughter) is more likely

171. Id. The authors cite scholars "working in th[e] growing area [of positive constitutional scholarship], such as Larry Kramer, Barry Friedman and Neil Siegal, [who] are striving to create a realistic, empirically grounded understanding of the dynamic relationship between public opinion and constitutional development." Id. at 591 .

172. We also realize that questions occasionally arise about the use of empirical research in legal scholarship. E.g., Brian Leiter, On So-Called "Empirical Legal Studies" and Its Problems, BRIAN LeITER's LAW SCHOOL REPORTS (July 6, 2010), http://leiterlawschool.typepad.com/leiter/2010/07/on-socalled-empirical -legal-studies.html. As explained more fully in the body of the Article, we designed a rigorous content analysis to explore and quantify in a scholarly and scientific way our anecdotal observations about the media's coverage of Supreme Court nominees. See infra Part II.C for discussion of the content analysis.

173. Bartow, supra note 70 , at 264.

174. Id. at 233 \& $n .55$ (citing the work of Anita Bernstein, Mary Anne Case, Martha Chamallas, Andrea Dworkin, Martha Ertman, Martha Fineman, Katharine Franke, Catherine MacKinnon, Martha Minow, Martha Nussbaum, and Joan Williams)

175. Dixon, supra note 31 , at 311-19.

176. Id. at 338 (suggesting that the focus on gender parity is misguided, arguing instead for the addition of judges who have a feminist ideology). Dixon acknowledges feminists' desire for equal numbers of women in the judiciary but concludes that "feminists must also weigh these benefits associated with the mere presence of a female justice on the Court against the importance of a justice's substantive approach to issues of central concern to feminists, such as abortion, pay equity, sex discrimination, sexual harassment, and an ongoing dialogue about the meaning of gender equality under the Equal Protection Clause." Id. at 336.

177. See id. at 338 (noting that a President might "exploit [feminists' focus on gender parity] in order to appoint an actively anti-feminist female judge" and that, in such an instance, feminists "should choose the feminist who is male"). 
to cultivate feminist values than one's gender. ${ }^{178}$ Other research suggests that party affiliation is the best predictor. ${ }^{179} \mathrm{We}$ do not equate being a woman with being a feminist and our project makes no distinctions between feminist and nonfeminist identities of lawyers or judges, nor do we equate female Justices with feminist viewpoints.

It is important, nevertheless, for women generally to be well represented in positions of power in the legal profession, regardless of their political ideology. Ginsburg not long ago expressed a similar sentiment in her remarks at Southwestern University School of Law, where she observed, "[a] system of justice is the richer for the diversity of background and experience of its participants. It is the poorer, in terms of evaluating what is at stake and the impact of its judgments, if its members-its lawyers, jurors, and judges-are all cast from the same mold." 180 Only when women have reached a place of more equal representation does it make sense to begin to argue for distinctions like those suggested by Dixon. We are deeply troubled by the media's portrayal of women who have attained powerful legal positions. Although we would not go so far as Professor Monopoli to legislate gender parity on the Supreme Court, ${ }^{181}$ we do believe it is imperative to women's advancement in the profession's power pipeline that we all engage in a critical examination of the media portrayal of women lawyers, especially those women lawyers who have attained significant positions of power. To this end, we investigated gendered portrayals of Supreme Court nominees, and asked how this knowledge might motivate the resolution of gender disparity in the legal profession's pipeline to power. We believe that the findings from our Media Study will prove similarly useful for those engaged in the exploration of public opinion and the Court, and also for those examining connections between public opinion and the advancement of women in the legal profession's power pipeline. Rhode and others are exactly right in their assessment that the pipeline "leaks" for various reasons, whether women choose motherhood or other paths. ${ }^{182} \mathrm{We}$ are troubled by more than leaks, however.

Equally problematic is the treatment of women who remain in the power pipeline; the proliferation of stereotypes and bias inherent in news media coverage may impact the professional experiences of these women themselves, and may systemically affect the way others perceive women who pursue positions of power. ${ }^{183} \mathrm{We}$ are reminded of

178. See Adam Glynn \& Maya Sen, Like Daughter, Like Judge: How Having Daughters Affect Judges' Voting on Women's Issues 1 (Mar. 25, 2011) (unpublished manuscript), available at http://scholar.harvard.edu /msen/files/judicialdaughters.pdf ("Looking at data from the U.S. Courts of Appeals, we find that . . . conditional on the number of children, judges with daughters consistently vote in a more liberal fashion on gender issues than judges without daughters.").

179. See Deborah Rhode \& Barbara Kellerman, Introduction, to WOMEN AND LEADERSHIP, supra note 30 at 18 ("Extensive research on U.S. legislatures finds that party affiliation is more important than gender in predicting votes on women's issues, and that ideology is more important in predicting sponsorship of legislation on these issues." (citations omitted)).

180. Ruth Bader Ginsburg, The Supreme Court: A Place for Women, 32 Sw. U. L. Rev. 189, 190 (2003).

181. See Monopoli, supra note 31 , at 45.

182. Rhode, supra note 60, at 7; see also Monroe \& Chiu, supra note 59, at 306.

183. "[A] rigid adherence to gender demarcation can be inaccurate and counterproductive, helping women advance into leadership positions in one instance . . but hurting them in others . ... Todd L. Pittinsky et al., The Great Women Theory of Leadership? Perils of Positive Stereotypes and Precarious 
Marilyn Frye's infamous birdcage metaphor in which she describes the difficulty inherent in recognizing oppression when employing a "myopic" focus. ${ }^{184}$ When one takes a step back and examines the cage (or oppressive structure) holistically, however, "[i]t is perfectly obvious that the bird is surrounded by a network of systematically related barriers, no one of which would be the least hindrance to its flight, but which, by their relations to each other, are as confining as the solid walls of a dungeon."185 Our Media Study reveals, on a macroscopic level, the proliferation of bias and stereotypes against women lawyers.

For some women, the stereotyping and bias might convince them to exit the power pipeline or dissuade them from entering it in the first place. For example, during the appointment process that ultimately led to Alito's nomination, at least two women (likely federal circuit judges Edith Hollan Jones and Edith Brown Clement) "withdr[ew] their names from consideration owing to concerns about the confirmation environment." 186 Such concerns may very well include the media circus that accompanies the confirmation process. Indeed, "[ $t]$ he most profound (and uncomfortable) questions at the moment may not be so much about the obstacles to women's leadership as about the appeal of leadership to women." 187 Further, gender stereotypes and bias perpetuate ideas more broadly about what a female leader "looks like"; this played out in the media coverage of the Sotomayor and Kagan nominations as discussed more fully below in Part III.

In contrast to traditional scholarship devoted to women, leadership, and power in the profession, which focuses upon identifying pathways to power, ${ }^{188}$ we aim to redefine the language used in assessing and accessing the power pipeline. Political scientist Ruth B. Mandel has observed that the "fit" for women in leadership may be uncomfortable because they must "travel in domains designed by and for men, replete with the residues of men's leadership for centuries." 189 She suggests that one way to make the fit more comfortable is for "women ... [to] redesign the . . . language of

Pedestals, in WOMEN AND LEADERSHIP, supra note 30, at 98 ("By characterizing and stereotyping leadership traits as gendered, we ultimately exclude, misrepresent, mold, and polarize the sexes, and leadership in general.").

184. FRYE, supra note 29 , at 4-5.

185. Id. at 5 (emphasis omitted).

186. Christine L. Nemacheck, Strategic Selection: Presidential nomination of Supreme COURT JUSTICES FROM HERBERT HOOVER THROUGH GEORGE W. BUSH 4-5 (2007).

187. Ruth B. Mandel, A Question About Women and the Leadership Option, in THE DifFerence “DIFFERENCE” MAKES, supra note 60, at 73.

188. For example, scholarship in this area has focused on women obtaining positions of power by following certain paths, such as acquiring power through their husbands or other men, or following a ladder from lower to higher courts. See, e.g., Rhode, supra note 60, at 3 ("For most of recorded history, women were largely excluded from formal leadership positions. . . Few . . . women . . . acquired leadership positions in their own right. Most exercised influence through relationships with men."); Carroll, supra note 13, at 440 (observing that the first women governors obtained their positions by replacing their deceased or impeached husbands); Martin et al., supra note 25 ("Research on the career backgrounds of women state supreme court justices and women federal court judges strongly suggests that women lawyers follow a judicial ladder from state courts to federal district courts to federal appellate courts." (citations omitted)). A similar "pipeline to power" has been identified for women who rise to higher-level political offices such as governor or member of Congress. Carroll, supra note 13 , at 446.

189. Mandel, supra note 187 , at 73 . 
leadership to make it friendly to both sexes." 190 Examining the language media employs to characterize nominees to the most powerful legal position in the nation is our response to Mandel's call.

\section{Supreme Court Nominee Media Study Rationale}

Though this research project emerged from our informal and unscientific selection and clipping of articles during the nomination period and confirmation hearings for Sotomayor and Kagan, we turned to a more empirical process to evaluate and measure these initial observations and questions regarding the intersections of media, gender, and Supreme Court nominees. After careful consideration, we ultimately decided to conduct a content analysis, employing a mixture of both qualitative and quantitative analysis, as the research method for our Media Study.

\section{Content Analysis as Research Method}

Although political scientists and legal and communication scholars have not specifically tackled the issues we address in this project, they rely on various empirical research methods, like content analysis, to gain an understanding of the complexities and intersections of gender ${ }^{191}$ and media. ${ }^{192}$ Content analysis, which involves the systematic examination and study of texts and other preexisting cultural material, ${ }^{193}$ is widely considered a mixed-method form of research that does not automatically signal either quantitative or qualitative methods and often includes the possibility of both. ${ }^{194}$ According to Martin Bauer, social psychologist with the Methodology Institute at the London School of Economics, content analysis is considered a "hybrid technique," meant to bridge the "quantity/quality divide in social research." 195 Unlike other forms of research, content analysis is unobtrusive and involves analyzing forms, in our case news articles, that are by nature constant, preexisting, and noninteractive. ${ }^{196}$

190. Id.

191. Kimberly A. Neuendorf, The CONTENT ANAlysis GuideboOK 202 (2002) (explaining how research examining gender roles across all sectors of media abounds; as a popular area of study, it crosses disciplinary lines and includes analysis of both text and images like literature, news, the Internet, magazines, film, television, children's books, music, stamps, music videos, and election coverage).

192. See generally Gender and Elections: ShapING the Future of AMERICAN POlitics (Susan J. Carroll \& Richard L. Fox eds., 2010); KAHN, supra note 34; WOMEN AND EleCTIVE OfFICE: PAST, PRESENT AND FUTURE (Sue Thomas \& Clyde Wilcox eds., 1998); WOMEN, MEDIA, AND POLITICS, supra note 34.

193. NEUENDORF, supra note 191, at 202; DANIEL RIFFE ET AL., ANALYZING MEDIA MESSAGES: UsING Quantitative CONTENT ANALYSIS IN RESEARCH 18-20 (2005); Martin W. Bauer, Classical Content Analysis: a Review, in Qualitative ResEarching WITH TEXT, IMAGE, ANd SOUND: A Practical HaNdBook 131, 133 (Martin W. Bauer \& George Gaskell eds., 2000); Patricia Lina Leavy, The Feminist Practice of Content Analysis, in FEMINIST ReSEARCH Practice 223, 227 (Sharlene Nagy Hesse-Biber \& Patricia Lina Leavy eds., 2007).

194. See Bauer, supra note 193, at 132; Leavy, supra note 193, at 227-28. Originally, content analysis was predominately quantitative, in that it primarily involved counting words or phrases in a particular text. Today, researchers view it as more of a hybrid form of research practice, one which involves both quantitative and qualitative characteristics.

195. Bauer, supra note 193, at 132.

196. Leavy, supra note 193 , at 227. 
Content analysis as a research tool allows researchers to look at and explore culture through the lens of the media. If culture is a place or site where ideas are created, disseminated, and consumed, then it can be useful to try to unravel or deconstruct the writings that are interconnected with how men and women are viewed. But media is not just a medium that captures the message; the explanation, indeed, is more complex. Sociology professor Patricia Leavy explains, "cultural artifacts do not simply reflect social norms and values; texts are central to how norms and values come to be shaped." 197 In our Media Study, we evaluate media articles as our texts or products of culture, observing and recording a series of variables designed to illustrate how nominees to the Supreme Court are portrayed. We find this analysis compelling because, as Shulamit Reinharz, sociology professor and director of the Women's Research Center at Brandeis University, and Rachel Kulick explain, "[t]he cultural products of any given society at any given time reverberate with the themes of that society and that era." 198

\section{Why This Content Analysis?}

Ten years ago, our specific Media Study would not have been possible because this is the first time in history that we have had a significant sample of women nominated to the Court. Even after O'Connor's nomination in 1981, twelve years passed and five new male Justices ${ }^{199}$ were nominated before another woman ${ }^{200}$ was selected to serve on the Court. In light of the timeliness, we chose the specific focus of our study - the media's depiction of Supreme Court nominees-for three reasons. First, the Supreme Court serves not as only a significant marker of power within our three branches of government but it is perhaps also seen as one of, if not the most, powerful institution within the legal profession. Unlike other powerful legal institutions, like law firms and corporations, the Court is subject to extensive media coverage in the public sphere. As such, it is uniquely situated to provide an opportunity for analysis and discussion. Second, because the Court occupies such a powerful position in the legal profession, there has been a great deal of anecdotal discussion ${ }^{201}$ about the media's coverage of nominees. At least in the context of our research interests, there has been some informal analysis ${ }^{202}$ but no major empirical study. Finally, largely as a practical matter, mainstream media articles covering the nominees to the Court are widely

197. Id. at 229.

198. Shulamit Reinharz \& Rachel Kulick, Reading Between the Lines: Feminist Content Analysis into the Second Millennium, in HANDBOOK OF FEMINIST RESEARCH: THEORY AND PRAXIS 257, 258 (Sharlene Nagy Hesse-Biber ed., 2007).

199. Antonin Scalia, Robert Bork, Anthony Kennedy, David Souter, and Clarence Thomas were all nominated to the Court in the years following Sandra Day O'Connor's appointment. Supreme Court Nominations, supra note 22.

200. Ruth Bader Ginsburg was nominated by President Clinton on June 14, 1993 and was confirmed on August 3, 1993. Id.

201. See supra note 21 and accompanying text discussing other sources that discuss media coverage of nominees.

202. See supra notes $164-74$ and accompanying text for a discussion of some studies on media coverage of nominees. 
viewed by the public. Capturing four decades of media coverage required some creativity and careful strategy as described more fully below.

\section{Why Focus on Nominees to the Supreme Court?}

We chose to focus on the media coverage of Supreme Court nominees, rather than the coverage of sitting Justices, because of the extensive and unusually invasive level of reporting that occurs during the nomination and confirmation process. As background, the Constitution provides that Supreme Court appointees are nominated by the President and confirmed with the "[a]dvice and [c]onsent" of the Senate, or, in other words, a majority vote by the Senate approving the appointment. ${ }^{203}$ Although confirmation hearings are not required, the Senate has taken testimony by the nominees and others since $1925 . .^{204}$ The process can be a matter of weeks or may extend several months, depending on the controversy surrounding the appointment. ${ }^{205}$ To determine our list of nominees, we selected only those individuals whose names were officially submitted to the Senate, and included them in the study whether confirmed or not. Our total pool was sixteen nominees. ${ }^{206}$

The media's coverage of a Supreme Court nominee is significant, in part, because, as Nina Totenberg explains, "[t]he only time a Supreme Court nominee is accountable at all to the public is before he or she is confirmed." 207 Thus, the media serves an important role for educating both the public and the Senate because

[t] he public deserves to find out beforehand about the men and women who, if confirmed, will be the final arbiters of the rules by which the country is governed. And the Senate is entitled to take the public's views into account when deciding whether to consent to the nomination. ${ }^{208}$

The media also bears significant responsibility in determining what the public learns about the nomination. Not only do "[t]hose who cover the Court . . . have views and find themselves more sympathetic to some results and to some Justices than to others," says Linda Greenhouse, but they also decide what is important and what will be reported. ${ }^{209}$ The nomination period also is significant in terms of media coverage

203. U.S. CONST. art. II, $\S 2$, cl. 2.

204. History of the Senate Committee on the Judiciary, U.S. SENATE COMM. ON THE JUDICIARY, http://www.judiciary.senate.gov/about/history/index.cfm (last visited Mar. 5, 2012).

205. For example, Justice Stevens was nominated by President Ford on November 28, 1975 and confirmed by the Senate (a vote of 98-0) on December 17, 1975. In contrast, Justice Thomas was nominated by President H. W. Bush on July 8, 1991 but not confirmed by the Senate (a vote of 52-48) until October 15, 1991. Supreme Court Nominations, supra note 22.

206. See infra Table 1 for a list of nominees in the study. We counted John Roberts's nomination only once-the first time he was nominated and introduced to the public. The subsequent withdrawal of his nomination and re-announcement as a candidate for the position of Chief Justice occurred outside of the introductory week timeframe, and we opted not to include his second nomination in our analysis.

207. Nina Totenberg, The Confirmation Process and the Public: To Know or Not to Know, 101 Harv. L. REV. 1213, 1229 (1988).

208. Id.

209. Greenhouse, supra note 159 , at $1548-49$ ("Of course, deciding what is important among the thousands of individual Court actions, which will be reported, and what pattern will be discerned from them can never be value-free. Those who make these judgments are the products of what they care about and also what they know."). 
because "one of the most significant public discussions of the Court happens when a vacancy on the high bench is being filled." 110 Thus, the media's portrayal of the nominee is as much about the nominee as a person as it is about the Court as an institution.

4. The Nominations of Justices Powell and Rehnquist: A Starting Place for Analysis

Our Media Study begins with the nominations of Justices Powell and Rehnquist. Both Justices were nominated and confirmed in late 1971 and sworn in during the first weeks of 1972. We selected this starting point mindful of the feminist movement's influence at the time.

The early 1970s were a powerful time in history, ${ }^{211}$ evidenced not just by a proliferation of gender-based Supreme Court cases including Roe v. Wade, ${ }^{212}$ but also by the passage of legislation like the Equal Rights Amendment ${ }^{213}$ and Title IX. ${ }^{214}$ In somewhat quick succession, the Supreme Court decided a number of cases that directly impacted women's lives. ${ }^{215}$ Each important in its own right, taken together these legislative and judicial events were particularly significant. The events serve as important markers of progress in the women's movement. ${ }^{216}$ These markers also coincide with the Powell and Rehnquist nominations, which, interestingly, carry their own tangential gendered significance. (During the vetting process of possible nominees, President Nixon considered a woman, Mildred Lillie, to fill one of these

210. Bybee, supra note 24 , at 40 (citing Agiesta, supra note 25 (reporting that polls conducted during the Kagan confirmation showed about forty percent of those surveyed were paying close attention to the process)).

211. See Leslie Friedman Goldstein, The Constitutional Rights OF WOMEN: CASES IN LAW AND Social CHANGE 334 (1988) ("The years 1971 to 1973 witnessed an explosion of women's rights developments at the Supreme Court level.").

212. 410 U.S. 113 (1973).

213. S.J. Res. 41,111 th Cong. (2010). In 1972, the ERA was passed by the Senate, 84-8 and the House 354-24. Although the ERA has never been ratified by the states (only 35 of the requisite 38 ), it has been reintroduced every year in Congress since 1982. Leah Donaldson, Female Legislators in the United States and Rhode Island, 16 Roger Williams U. L. REV. 278, 291 (2011). Nonetheless, the creation of constitutional language surrounding gender equality is significant.

214. Education Amendments of 1972 , Pub. L. No. $92-318, \S 901,86$ Stat. 235,373 (codified as amended at 20 U.S.C. $\S 1681$ (2006)). Title IX was renamed in 2002 the Patsy T. Mink Equal Opportunity in Education Act, in honor of its primary author, Congresswoman Mink. Act of Oct. 29, 2002, Pub. L. No. 107-255, 116 Stat. 734.

215. E.g., Frontiero v. Richardson, 411 U.S. 677, 678-79, 690-91 (1973) (holding that a statute violated the Due Process Clause when, for administrative convenience only, it prevented spouses of female service members from being claimed as dependents unless they were in fact dependent on the service member for over one-half of their support, thereby preventing them from receiving benefits that were available to spouses of male service members); Eisenstadt v. Baird, 405 U.S. 438, 443 (1972) (holding that a statute prohibiting contraception violated the Equal Protection Clause); Reed v. Reed, 404 U.S. 71, 72-73, 76-77 (1971) (holding that a statute violated the Equal Protection Clause when it preferred males over females in instances where an equally qualified male and female petitioned to administer the same estate).

216. See MARTIN \& JURIK, supra note 75, at 5-6 (discussing legislative and judicial victories for women's rights and noting that "[f]eminist goals, such as women's rights to paid employment, equal pay for equal work, and jobs in all occupations without limitations imposed by sex discrimination, became more socially acceptable"). 
vacancies. ${ }^{217}$ ) Although a project reaching all the way back in time to the Court's origins might provide a more wholly comprehensive picture, ${ }^{218}$ given budget and time constraints, together with the gendered lens through which this project was conceptualized, we selected the Powell and Rehnquist nominations as an appropriate place to begin the Media Study.

\section{Research Methodology}

To conduct the first phase of the Media Study, we created a unique collection of articles drawn from the New York Times and the Washington Post. In deciding to focus on these sources, we followed a selection process similar to that used by other experts in the field. We strove for both ideological balance as well as expertise in reporting on the Court. ${ }^{219}$ We gathered every news article, opinion piece, and letter to the editor published in the Times and Post, from the date the President announced 220 the

217. Lillie's name was removed as a possibility after the American Bar Association refused to extend its support to her candidacy, as discussed in greater detail below. It is worth noting that Lillie was not the first woman to appear on a president's shortlist for nominations. The first woman was Soia Mentschikoff, though ultimately President Lyndon B. Johnson named Abe Fortas. NEMACHECK, supra note 186, app. at 150-55. Until the nomination for the vacancy filled by Justice Sotomayor, only sixteen women had appeared on the shortlist for Supreme Court nominations. Id.

218. In a subsequent phase of this project we may extend our Media Study back at least to the nomination of Thurgood Marshall, the nation's first African-American Supreme Court Justice. We believe that the analysis of the media's coverage of race in the context of Supreme Court nominations will yield important and significant findings, both in the context of our study on gender and as an independent analysis.

219. See Mark Obbie, Winners and Losers, in BENCH Press, supra note 121, at 161 ("[The New York Times and the Washington Post] are generally perceived as the two most important newspapers covering the Supreme Court and the Court nominations. With their extraordinarily deep reporting resources, in numbers of journalists and expertise, they help set the agenda for the debate."); $c f$. DAVIS, supra note 163, at 162 (selecting wire copy of the Associated Press for conducting a content analysis of Supreme Court decisions because it is the "most widely utilized source of information about the U.S. Supreme Court," though acknowledging that "[l]arge metropolitan dailies—-such as the New York Times [and] Washington Post" have "their own reporter at the Court for whom the Court is a major assignment of their beat"). Additionally, the New York Times and the Washington Post have served as invaluable data for similar studies of media impact on the judiciary. See JAMIESON, supra note 29, at 169 ("analyz[ing] all the print coverage found in the New York Times, Washington Post, and major state newspapers covering the federal elections featuring women in 1990, 1992, and 1993"); Ansley \& Sellers, supra note 165, at 302 (analyzing all stories appearing during the Alito nomination period from the Washington Post and the Washington Times "due to their ideological counter-balance and extensive coverage of the Alito nomination"); Bybee, supra note 24, at 146-47 (using the New York Times, Washington Post, and Los Angeles Times "to identify the images of judging projected by the entire confirmation coverage [for Kagan]" and "reason[ing] that the totality of material published by the newspapers would be a fair sample of the complete universe of confirmation coverage generated by all media," while also noting that "[ $\mathrm{t}] \mathrm{o}$ learn how three large newspapers [including the New York Times and the Washington Post] framed the confirmation process for their readers is . . to gain a good understanding of how the media as a whole represented Kagan's journey from the committee hearings to the final vote"); Davis, supra note 38, at 1073, 1075 (using the New York Times to conduct empirical study comparing the "[p]ress coverage of six recent controversial nominees from the period of 1986-1991 . . . with the press coverage of six nominees from the period 1969-1971"); Xenos, supra note 164, at 492 (analyzing all stories appearing in the New York Times during the Alito nomination period, and "allow[ing] the Times to represent mainstream newspaper coverage and also to serve as the reference point for our investigation of blog coverage, literally treating it as a "paper of record"').

220. NEMACHECK, supra note 186 , at 26 ("Once the candidate to the Court is announced by the president, the confirmation stage of the nomination process officially begins.”). 
nomination ${ }^{221}$ to the date confirmed by the Senate or withdrawn from candidacy within the date range of 1971 to 2010.222 The collection is housed in a specialized, searchable electronic collection developed by librarians at Michigan State University College of Law John F. Schaefer Law Library. 223

Once complete, we created a comprehensive list of over fifty variables to be coded for each article in the collection. The variables embrace a range of information about the articles and can be broken down into three distinct categories. First, we coded for characteristics without regard to the substance of the article, like word count, placement within the newspaper, name and sex of the author, and whether a photo accompanied the article. ${ }^{224}$ Second, we examined a number of variables related to the actual content of each piece. Did the article mention, for example, the parental or marital status of the nominee, the nominee's views on abortion and other issues, or the nominee's appearance? Finally, we coded for a series of nuanced elements of the article like the tone of the headline, lead paragraph, and overall article, as well as whether gender was mentioned in relation to the nomination.

The coding tool was created and used to perform textual analysis of each article. Following the design of the coding tool and preliminary coder training, the reliability

221. Because our focus is on the media coverage of nominees, sometimes we made a decision to begin analysis of the nomination period on the day following the President's announcement. An announcement of a nominee by the President on one day might not yield media coverage until the next due to constraints of news publication schedules. As an example, Justice Sotomayor's nomination was made public at noon on May 26, but newspaper coverage of the nomination did not occur until the following day, May 27. For purposes of our study, the analysis of Sotomayor's coverage began on May 27.

222. Although our original search included any article in which the nominee's name appeared, we ultimately refined the field to include only articles that were explicitly about the nominee or nomination in question. This sufficiently narrowed our dataset and furthered our interest in capturing how the nominees are portrayed by media. Other studies using the New York Times or the Washington Post to evaluate media coverage of Alito and Kagan during their nomination period followed a similar process. For example, Professor Bybee's study of newspaper coverage during the Kagan nomination period, which he defined as June 28, 2010 to August 5, 2010, yielded twenty-two news articles and ten editorial/op-ed pieces from the New York Times, and forty-one news articles and twenty-four editorial/op-ed pieces from the Washington Post. Bybee, supra note 24 , at $146 \mathrm{tbl}$. 1 . To collect the articles used in his study, Bybee used the built-in search tool for each paper's website. Id. at 145; see also Xenos, supra note 164, at 493 ("Our Lexis-Nexis search of [New York] Times stories featuring 'Alito' in the headline or lead paragraphs between October $29^{\text {th }} 2005$ and February $7^{\text {th }} 2006$ yielded a total of 264 stories. Filtering out duplicate stories, unsigned editorials, and items that fell below a minimum threshold of 325 words (mainly corrections and simple photo captions) reduced the corpus to 153 stories.").

223. The data collection was conducted at the Michigan State University College of Law John F. Schaefer Law Library by reference librarian Brent Domann. A research assistant gathered newspaper articles by searching commercial databases. New York Times articles from 1980 to the present were taken from Westlaw, and Washington Post articles from 1980 to the present were taken from Lexis Academic. Articles prior to 1980 were gathered from the ProQuest Historical Newspapers database. Each nominee was searched within each source by name and with dates restricted to those during which the nominee was a candidate, that is, from the date of the nomination announcement until the date of confirmation or the date the nominee was withdrawn as a candidate. The citations for results were saved and later retrieved by batch due to the sheer volume of search results (roughly 4,000). All search hits were filtered for duplicate entries and false positive hits. The resulting materials were saved as Microsoft Word, text, or Adobe PDF files and were subsequently loaded into an electronic collection tool built with Greenstone software.

224. Although analyzing the actual photographs is well beyond the scope of the initial phase of the project, we may embark on such analysis at a later point. 
of the tool was assessed informally though a percentage agreement analysis of three coders across thirty-eight indicators for fifteen randomly selected articles. After the coding tool was updated and refined ${ }^{225}$ and additional coding instructions were provided to all independent coders, an official pilot test was conducted on a random sample set of five articles, by three independent coders, across fifty-four separately coded indicators. The results of the pilot test were analyzed using Krippendorff's alpha ${ }^{226}$ due to its ability to ascertain reliability across various levels of data while also accounting for chance agreement among coders. ${ }^{227}$ Reliabilities ranged from a high of 1.0 (no variability among coders) to 0.7 . Although some research may require a higher metric for agreement ( 0.8 or higher), the exploratory nature of this research as well as the limited number of items used for reliability testing suggests that this is a sufficiently high reliability measure. ${ }^{228}$ One variable-mentions of sexual orientation of the nominee-had an alpha betow 0.5 and was removed from subsequent analysis.

Explicit parameters for our content analysis appear in a comprehensive coding protocol, the Codebook. ${ }^{229}$ Two research assistants working under our direction completed the actual coding process. The research assistants received comprehensive training, including lengthy review of the Codebook. They were not advised of our research hypotheses, however. The data findings were analyzed using IBM SPSS predictive analytics software.

Throughout the process of conducting the Media Study, in addition to overseeing the coding of articles in our collection, we each individually read hundreds of articles about the sixteen nominees to the Court. This process has revealed an extensive amount of information responsive to our questions about the connections between gender and the media's portrayal of Supreme Court nominees. As a whole, our research supports the claims made by other scholars that "[w]hen the media cover women leaders, they are often portrayed in a stereotypical manner." 230

Our Media Study is being conducted in phases. This Article documents the results from Phase One, which focuses on coverage by the New York Times and the Washington Post during the first week that follows the announcement of a nominee by the President (i.e., the introduction week). Phase Two will examine the same media sources during a different time period, the confirmation hearing. Later phases may include coding all articles appearing during the entire confirmation process as well as online blog coverage of the nominees.

225. NEUENDORF, supra note 191, at 132 ("The goal in creating codebooks and coding forms is to make the set so complete and unambiguous as to almost eliminate the individual differences among coders.").

226. The program ReCal3 was utilized for calculations. ReCal3 is a freely available Internet program specifically designed to calculate various intercoder reliability metrics, including Krippendorff's alpha, for three or more coders of categorical level data. See generally Matthew Lombard et al., Content Analysis in Mass Communication: Assessment and Reporting of Intercoder Reliability, 28 HUM. COMM. RES. 587 (2002).

227. RIFFE ET AL., supra note 193, at 132-33.

228. See generally Klaus Krippendorff, Reliability in Content Analysis: Some Common Misconceptions and Recommendations, 30 HUM. COMM. RES. 411 (2004).

229. At the conclusion of this project, we plan to make the Codebook as well as the complete coding dataset available to researchers and others with an interest in the media's portrayal of Supreme Court nominees.

230. KLENKE, supra note 56 , at 118. 
We define the introduction week as the seven days that follow the President's announcement of a nominee. We chose to focus on this period first because the sample offers a sufficient body of data to conduct a rigorous content analysis and also allows us to contrast media coverage between the introduction period and other points in time during the nomination process. Other scholars have followed similar selection criteria. Professor and journalist Mark Obbie, for example, conducted a content analysis of the "[r]esults-oriented legal journalism"231 surrounding Justice Alito's confirmation process. ${ }^{232}$ Obbie selected the first week of news stories for his analysis because it captures the time period during which most media consumers "form first impressions of a nominee." 233 Further, he notes that " $[t]$ he news coverage at first is intense, then it recedes, with occasional bursts of activity; and finally it spikes during the Senate's deliberations." 234

Before presenting our results, several research limitations should be noted. First, although the New York Times and the Washington Post are generally acknowledged as appropriate sources for conducting representative content analysis and empirical studies, we acknowledge that a survey of additional newspapers may be informative. Similarly, Phase One of this project examines only eight days of media coverage, so it is limited in scope and provides only a snapshot of the total coverage during the confirmation period. Dozens if not hundreds of articles were written about each nominee during the time between the announcement and confirmation or withdrawal. The introduction week includes approximately ten to fifteen percent of the total coverage a nominee received. For example, 386 articles appeared in the Washington Post and New York Times about Kagan, only fifty-seven of which were published during the introduction week.

We also recognize that some might suggest our focus on the media's portrayal of nominee appearances based upon gender simply perpetuates the problem. As Katherine Bartlett observes, "[a] problem for feminists is that calling attention to the importance of dress and appearance matters may reinforce that importance and, accordingly, the power of dress and appearance norms to oppress women." 235 Although this might be a risk, we believe it is a risk worth taking because of the benefits that might be realized from addressing gendered media portrayals of Supreme Court nominees in a scholarly, scientific way.

231. Obbie defines results-oriented legal journalism as "reporting on the outcome of a court case without acknowledging the legal authority that the court cited in reaching that outcome." Obbie, supra note 219, at 159 (emphasis omitted).

232. Obbie's research focuses exclusively on the nomination of Justice Alito to the Supreme Court. He is critical of the news media's tendency to omit critical details in their reporting on the record of Supreme Court nominees, characterizing their tendency as "one of sloppiness and ignorance." Id. at 154 . He is concemed by the misinformation that is communicated to the masses. Obbie asserts, "[w]hen journalists boil all substance out of the law before serving it to the public, they distort the meaning of the rule of law." Id.

233. Id. at 162 .

234. Id.

235. Bartlett, supra note 107 , at 2580 . Bartlett notes that " $[\mathrm{t}]$ he dilemma is the same one feminists face in addressing the larger matter of sexual difference: taking account of sexual difference reinforces it, which in turn, at present, means reinforcing sex-based disadvantage." Id. (footnote omitted). Further, "responding to dress and appearance matters as important participates in the validation of appearance as a basis for judging individuals and, thereby, for constraining women." Id. 
Furthermore, we do not mean to suggest that power is found only in a position like Supreme Court Justice; rather, it seems that if the most highly accomplished and credentialed women in the legal profession remain subject to bias and stereotyping in the media, surely many other women in the profession experience these phenomena to a certain degree as well. As touched upon in the foregoing literature review, there are also other important, interesting ways of looking at the media's depiction of Supreme Court nominees that are simply beyond the scope of this Article, such as the influence of race in the media's depiction of nominees ${ }^{236}$ or the influence of media in shaping public opinion. ${ }^{237}$

Finally, the Media Study does not purport to demonstrate the concrete consequences of the gendered media coverage documented by our research. We leave for future scholars and researchers the task of evaluating the extent of the harm caused by the disparate treatment identified by our study, and predict, based upon the preliminary findings, that future research will identify at least one aspect of harm to be the reluctance of qualified women to enter and/or remain in the legal profession's pipeline to power. Further, and perhaps most importantly, we agree with Kathleen Hall Jamieson's assessment that "[t]he first step in overcoming a double bind is seeing it for what it is." 238 To this end, our Media Study illuminates many of the gendered binds that confront women.

\section{FIRST IMPRESSIONS OF NOMINEES IN THE MEDIA: THE INTRODUCTION WEEK}

\section{A. Study Results}

We established a number of hypotheses based upon anecdotal observations about the media's coverage of recent nominees to the Supreme Court. Each hypothesis was united by a common theme that evaluates whether a relationship exists between the gender of Supreme Court nominees and how they are portrayed by the media. We are mindful that our preconceived ideas about gender and the coverage of nominees necessarily required the use of an objective measure to evaluate the media coverage; this informed our decision to undertake a quantitative study. The preliminary findings generated from Phase One of our content analysis, focusing exclusively on the introduction week for each nominee, demonstrate that news coverage is emblematic of the persistent struggle for equal access to and ascension in the power pipeline for women in the legal profession. This conclusion is supported by an overarching theme in our preliminary findings exposing a subtle but pervasive and striking gender imbalance in the coverage of nominees. To be clear, this first phase of research offers only preliminary findings. The data is illuminating, and in many instances informs our refinement of existing questions for further study and uncovers an entirely new set of questions to be considered in future research. Our preliminary findings are a first point of inquiry into a realm deserving of significant attention; we hope that other scholars

236. See supra note 22 for a source discussing media coverage of Justice Clarence Thomas.

237. See supra notes 118-24 and accompanying text for a discussion of the role of media in shaping public opinion.

238. JAMIESON, supra note 29 , at 190. 
will join this discussion and we look forward to sharing results of our own subsequent research. Set forth below are our preliminary findings along with a discussion of the relevant results from the content analysis covering the introduction week of media coverage for the Supreme Court nominees.

\section{Preliminary Finding 1: Female nominees receive more coverage (in terms of quantity and length of articles) than male nominees during the introduction week.}

We were somewhat surprised by the results about the quantity of media coverage of male and female nominees. Initially, we predicted that male nominees would receive more coverage than female nominees, but this is not reflected in the data. Rather, we observed that, on average, there was actually more media coverage of the female nominees, at least in terms of the number of articles written, and to a lesser extent the number of words written. We speculate that one possible rationale for this phenomenon is that justices who deviate from the white, male, married, heterosexual norm are written about more frequently perhaps because of their relative novelty.

The average number of articles written about female nominees during the introduction week was 54.2 articles, compared to an average of 47.7 articles written about the male nominees. Independent sample t-tests indicated that this relationship was not statistically significant, however $(\mathrm{t}=0.546, \mathrm{p}=0.594) .{ }^{239}$ The trend also favored women for the average length of the story, with the female nominees averaging 1,081.4 words per story and males averaging 959.1. An independent samples t-test indicated that this difference was statistically significant $(t=2.191, p=0.029)$. Counter to the direction of the hypotheses, the data indicates that female nominees receive more coverage in terms of number of articles and that these articles tend to be longer stories. The total word count for male and female nominees is documented in the table below. ${ }^{240}$

\begin{tabular}{|l|c|c|}
\multicolumn{1}{l}{ Nominee } & Articles & Word Count \\
\hline Kagan & 57 & 43,887 \\
\hline Sotomayor & 78 & 78,043 \\
\hline Miers & 62 & 60,023 \\
\hline Ginsburg & 44 & 55,173 \\
\hline O'Connor & 30 & 30,505 \\
\hline Alito & 68 & 66,247 \\
\hline Roberts & 98 & 94,529 \\
\hline Breyer & 26 & 31,698 \\
\hline Thomas & 57 & 55,173 \\
\hline Souter & 55 & 55,686 \\
\hline
\end{tabular}

239. See infra Table 3 for data on the average number of articles written about male and female nominees during the introduction week.

240. The articles written about Powell and Rehnquist were retrieved using an alternate search mechanism which did not generate word counts, so they are not included in our analysis for this variable. 


\begin{tabular}{|l|l|l|}
\hline Kennedy & 25 & 23,839 \\
\hline Bork & 43 & 41,800 \\
\hline Scalia & 44 & 41,276 \\
\hline Stevens* $^{*}$ & 21 & 12,754 \\
\hline Powell* $^{*}$ & 29 & $\mathrm{n} / \mathbf{a}$ \\
\hline Rehnquist* $^{*}$ & 37 & $\mathrm{n} / \mathbf{a}$ \\
\hline
\end{tabular}

Preliminary Finding 2: The gender or sexuality of female nominees is mentioned more frequently than the gender or sexuality of male nominees during the introduction week.

The mention of a nominee's gender or sexuality can be seen as both positive and negative. On the one hand, reporting that a nominee is a woman emphasizes the importance of diversity (or lack of diversity). It also can be seen as celebrating the achievement of a previously excluded group as having attained elite status. On the other hand, focus on a nominee's gender or sexuality can distract from reporting on a nominee's qualifications and merit for the position. It also can perpetuate stereotypes and token status.

Not surprisingly, as the first female nominee to the Court, O'Connor's gender was referenced in numerous articles. In some instances, the reference was positive; that is, acknowledging the history of exclusion for women in the law and identifying her nomination as a step forward. For example, one reporter referenced the words of Phyllis Segal, then-director of the National Organization for Women's Legal Defense and Education Fund, who spoke of "Myra Bradwell's failure to crack the Illinois bar, of Belle Mansfield's success in 1869, in the more tolerant state of Iowa, in becoming the nation's first woman admitted to the bar" and contextualized "Judge O'Connor as a pioneer[ing] woman."241 Years later, noting the historic occasion presented by three women Supreme Court Justices, another reporter observed this "was a benchmark that women's law groups celebrated as a major step toward a sex parity that has eluded the United States Supreme Court compared with the highest courts of several states and countries."242

We observed that most references to gender in the headlines, however, were negative; that is, distracting from the reporting on the nominee's merit, perpetuating stereotypes, and/or undermining the nominee's qualifications. At times this is seen subtly in headlines like "The Nomination of Mrs. O'Connor."243 The seemingly subtle reference to gender takes on a different significance, however, when considering that O'Connor is the only nominee whose name included "Mr.," "Mrs.," or "Ms." in a

241. Francis X. Clines, About Washington; An Occupation of Civil Life, N.Y. TIMES, July 11, 1981, § 1, at 8 .

242. Mark Leibovich, Reshaping Court's Culture, a Woman at a Time, N.Y. TIMES, May 11, 2010, at A15.

243. Editorial, The Nomination of Mrs. O'Connor, WASH. POST, July 8, 1981, at A22; see also Only Ultras Fight Mrs. O'Connor for the High Court, N.Y. TIMES, July 12, 1981, $\$ 4$, at 1. 
headline, reflecting further stereotyping. ${ }^{244}$ There are also explicit negative references in the articles themselves. For example, one reporter quoted a source who characterized O'Connor's voice as "high-pitched . . ., almost like a young girl's" and another who attributed her election to a judgeship on the Maricopa County Superior Court to "the year of the woman" where "[e]very woman on the ballot in the state of Arizona won that year." 245 Another reporter described the nomination of O'Connor as politically "cute."246

As an additional example of explicit references to O'Connor's gender that distracted from reporting on her qualifications and merit for the position, the reporter in one article highlighted President Reagan's "mistake" in which he "admitted that his appointment of Judge Sandra Day O'Connor . . . culminated a search for a highly qualified woman" and "contradicted the official White House position that selection of the nation's first female justice had nothing to do with her sex."247 Another reported that "Judge O'Connor had never been an activist on any issues related to feminism."248

The gender of female nominees continued to be a focus of media coverage even after the first woman was confirmed to the Court. When the second woman was nominated, one author urged senators to in the headline to: "Treat Judge Ginsburg Like a Man."249 Another reporter noted that Ginsburg's "whole career, not only her gender," rendered her qualified for the position. ${ }^{250}$ The New York Times and the Washington Post repeatedly reminded readers of Harriet Miers's fondness for "girls' nights out"251

244. For a discussion on the use of honorifics by the media, see JAMIESON, supra note 29, at 165-66. Jamieson notes that "[i]n 1977 the UPI Stylebook instructed reporters not to 'use Mr. in any reference unless it is combined with Mrs.' . . . [and] the style manual currently in use at the Philadelphia Inquirer makes no distinction," directing that reporters "not use the courtesy titles Miss, Mr., Mrs., or Ms.' Id. Interestingly, although not appearing in the headlines, a number of articles for female and male nominees included honorifics within the body of the article. For example, seven articles referenced "Ms. Sotomayor," eight referenced "Mr. Alito," and fourteen referenced "Mr. Roberts" in the article text. To find these references, we used a search function to scan the text of each set of justice-specific articles. For example, in the set of articles about Sotomayor, we searched for "Ms. Sotomayor" in the collection. The search revealed seven articles that we subsequently read individually to ensure the accuracy of the search results.

245. Fred Barbash \& Ted Gup, Trailblazer; Still Deeply Rooted in the Ranch, Pioneer's Kin Nears High Court; Court Nominee Preserves Pioneer Tradition, WASH. POST, July 12, 1981, at A1. Another year dubbed "The Year of the Woman" was 1992, about which Senator Barbara Mikulski observed: "I personally didn't like the title. Like we only get one year per century. Like the year of the dog. The year of the zebra." JAMIESON, supra note 29, at 167.

246. Richard Cohen, Politics; O'Connor Nomination Is Very Clever Politics, WASH. PosT, July 14, 1981 , at B1 ("It is interesting, then, that a whole bunch of people, liberals included, think that Ronald Reagan's nomination of Sandra O'Connor is cute-very clever politics. It puts a woman on the court, therefore fulfilling a campaign promise ....").

247. Howell Raines, Reagan's Shift to the Center Raises Clamor on the Right, N.Y. TIMES, July 12, $1981, \S 4$, at 1 (internal quotation marks omitted).

248. Steven R. Weisman, White House Rebuts Charges that Nominee Has Voted for Abortions, N.Y. TiMEs, July 9, 1981, at A17.

249. Kathleen Quinn, Treat Judge Ginsburg Like a Man, N.Y. TIMES, June 20, 1993, § 4, at 17.

250. See Mr. Clinton Picks a Justice, N.Y. TIMES, June 15, 1993, at A26 (stating that Ginsburg's career and gender stand for the principle of accepting or rejecting people and ideas on their merits, rather than prejudice or stereotypes),

251. Todd S. Purdum \& Neil A. Lewis, Hard-Working Advocate for the President, N.Y. TIMES, Oct. 4, 2005 , at A1. 
to engage in "a lot of girl talk"252 with "Condi and the other single girls,"253 referencing then-Secretary of State Condoleezza Rice. Even with the most recent nomination of Kagan, the gendered focus persisted, with headlines such as "Reshaping Court's Culture, a Woman at a Time"254 appearing in media.

Beyond these anecdotal examples, however, lies a revealing empirical truth. Stories about female nominees $(n=272)$ mentioned their gender or sexuality more often than stories about male nominees $(\mathrm{n}=503) .{ }^{255}$ In over fifty percent of the articles written about female nominees, the author referenced the nominee's gender or sexuality in relation to the nomination. Conversely, almost none of the articles written about male nominees mentioned their gender or sexuality. Even news coverage about the nomination of Kagan referenced her gender repeatedly, despite the reality that a woman on the Court was no longer a novelty. When reporters treat "women as exceptions, [they] reinforce this assumption." ${ }^{256}$ This in turn perpetuates a minority's token status, even when, in reality, they may have moved well beyond being the "first" or "only" woman in such a role.

Although extensive analysis of race is beyond the scope of Phase One of our Media Study, we were also struck by the numerous references to a nominee's race when the nominee was not white. The relatively small number of Justices represented in the Media Study does not permit formal statistical analyses to be conducted for this intersection; descriptive statistics, however, are revealing. In the articles about Thomas, for example, his race was explicitly mentioned in seventy-four percent of the articles. In the case of Sotomayor, mention of her race occurred in ninety-four percent of the articles; perhaps as the first Latina woman nominated to the Court, the unique intersection of race and gender contributed to this phenomenon. We find this data compelling; it suggests that indeed we have not yet moved beyond pervasive disparity, at least in terms of drawing attention to minority status. Gender and race, as deviations from the white, male, married, heterosexual norm, still tend to be perceived as novel and newsworthy.

Sometimes the racial and gender differences are discussed in the context of how the nominees will rule on cases before the bench. ${ }^{257}$ Indeed, the media scrutinizes the nominees' own remarks about the relevance of their background or experiences. For example, both Sotomayor and Alito made comments before their nominations about

252. Elisabeth Bumiller, A Place at the Table for Miers and High-Level Friends, N.Y. TLMEs, Oct. 10, 2005, at A17.

253. Michael Grunwald et al, A Deep Dedication to the President, and to Her Work, WASH. Post, Oct. 4,2005 , at A01.

254. Leibovich, supra note 242.

255. See infra Table 4 for statistics showing that articles were more likely to mention physical appearance when the nominee discussed was female.

256. JAMIESON, supra note 29 , at 167.

257. See James Oliphant \& David G. Savage, The Nation: Sotomayor Hearings Show Diverse Takes on Diversity, L.A. TIMES, July 19, 2009, at 3 (noting that several legal experts believe that "Sotomayor's Puerto Rican heritage and Bronx upbringing will have an effect inside the Supreme Court"). 
how their personal life experiences may impact their decisions, ${ }^{258}$ but the way in which these comments were portrayed differed significantly. In a lecture in 2001 on the role her background played in her jurisprudence, Sotomayor said, "I would hope that a wise Latina woman with the richness of her experiences would more often than not reach a better conclusion than a white male who hasn't lived that life."259 Sotomayor was vilified in the media for this remark, and President Obama was taken to task for selecting a nominee based upon qualities that included "empathy." 260 Although our coding did not specifically capture the quantity of media attention devoted to this quote itself, our analysis revealed that indeed a majority of articles included a reference to these particular words. A New York Times article reveals how this gendered double standard plays out:

Judge Sotomayor has fueled the discussion by suggesting that gender and ethnic heritage can play a role in judicial decision-making. Yet Judge Samuel A. Alito Jr., nominated by [President] Bush in 2006, made similar remarks, telling senators that in cases involving immigration, "I can't help but think of my own ancestors." 261

The sentiments expressed surrounding the impact of Alito's Italian "ancestors" and Sotomayor's Latina heritage are strikingly similar; yet, the media focus differed substantially, and the fallout from Sotomayor's remarks resonated continually during her nomination. Contrast the first President George Bush's praise for his Supreme Court nominee Clarence Thomas, describing him as "a warm, intelligent person who has great empathy." 262 Another point of comparison is the emphasis placed on Sotomayor's ancestry. Multiple articles referenced her Latina background in the first line, ${ }^{263}$ whereas the ancestry of other nominees, if even mentioned, appears later in the article, if not the last paragraph, as was the case in a reporter's mention of Scalia "who would be the first Justice on the Court of Italian descent." 264

More recently, the media has explicitly scrutinized the sexuality of female nominees. For example, one reporter observed that "double-entendre wisecracks about Kagan's softball prowess were all the rage on Fox News and MSNBC."265 This same reporter noted that " $[t]$ hose rumors have chased all unmarried Supreme Court justices

258. See Sheryl Gay Stolberg, Buzzwords Shape the Debate over Confirmation, N.Y. TIMES, May 29, 2009, at A15 (noting Justice Alito's admission that he "think[s] of [his] own ancestors" when faced with immigration cases).

259. Peter Baker \& Jeff Zeleny, Obama Chooses Hispanic Judge for Supreme Court Seat, N.Y. TIMES, May 27, 2009, at Al.

260. Id.

261. Stolberg, supra note 258

262. Sheryl Gay Stolberg, Say It With Feeling? Not This Time Around, N.Y. TIMES, May 29, 2009, at A15.

263. See, e.g., Dan Eggen \& Paul Kane, Obama Says Judge Regrets Wording; GOP Leaders Try to Rein in Reactions to Sotomayor's 2001 Speech, WASH. POST, May 30, 2009, at A01 (stating that President Obama said Sotomayor regrets saying a "wise Latina" would make better decisions than a white male); David M. Herszenhorn \& Carl Hulse, Parties Plot Strategy as Sotomayor Visits Capitol, N.Y. TmES, June 3, 2009, at A20 (stating that Senate Democrats sought to defuse criticism of Sotomayor's comment that a Latina judge like herself might have better judgment than a white male).

264. James Reston, Hear Ye in the Court, N.Y. TIMES, June 18, 1986, at A35.

265. Frank Rich, Op-Ed., A Heaven-Sent Rent Boy, N.Y. TIMES, May 16, 2010, at WK10. 
or would-be justices loathed by the right, whether Republicans like David Souter and Harriet Miers or the previous Obama choice, Sonia Sotomayor."266 Our Media Study showed, however, that although rumors might indeed have floated about Souter, his sexual orientation was not explicitly mentioned, at least in articles that appeared during the introduction week. Our future research will reveal whether this remains the case throughout the duration of the nomination period.

Although not effectively documented through quantitative analysis, we did observe in the qualitative analysis explicit attention paid to the sexual orientation of single, female nominees Kagan and Sotomayor. This fascination plays out in several ways, sometimes intersecting with issues of marriage and children, but often lending itself to discussion of whether Kagan or Sotomayor are lesbians. There is an air of confusion, trying to proffer explanations for their unmarried "plight." An article in the Washington Post explained about Kagan, "[s]he's not gay, okay? Actually, the all-toopublic discussion about the ought-to-be private topic of Elena Kagan's sexuality would be easier if the Supreme Court nominee were gay."267 Sotomayor's sexual orientation was discussed far less frequently than Kagan's, intersecting tangentially with the extensive attention paid to her gender and race. None of the media coverage of the male nominees to the Court focused on their sexual orientation in this way. The data generated from our Media Study related to issues of gender, race, and sexuality leads us to conclude that the standard by which Supreme Court nominees are assessed in the media is one against the backdrop of a white, married, male, heterosexual norm. We speculate that this is emblematic of the standard by which leaders in the legal profession generally are assessed, too.

Preliminary Finding 3: The limited sample of articles tends to show that appearance of female nominees is mentioned more frequently than the appearance of male nominees, but more data is needed.

We used two different approaches to examine how the media constructs appearance. First, we asked whether the nominee's appearance generally was mentioned within the text of the article. ${ }^{268}$ Second, we asked whether a photograph was included along with the text. The results of both inquiries are illuminating.

The evaluation of appearance within the article text included several variables, ranging from mentions of general appearance to more specific appearance variables such as body posture and physical traits. A series of independent t-tests revealed that the general hypothesis regarding more frequent references to appearance for female nominees could not be supported given the few number of articles mentioning appearance during the introduction period, regardless of nominee gender $(t=<1.34$, $\mathrm{p}=>0.203$ ).

266. Id.

267. Ruth Marcus, Editorial, Smart Women, Fewer Choices, WASH. POST, May 14, 2010, at A15 (paragraph break omitted).

268. As a related matter, we also coded for more specific aspects of how appearance was discussed, like body posture, inherent trait, or adornment (clothing, pantyhose, etc.). Those distinctions may be explored in greater detail in future work. 
Although not statistically significant, the data referencing appearance does identify a trend that we intend to explore more fully during subsequent phases of analysis. The appearance of female nominees was mentioned more than twice as often as the male nominees, though the number of articles proved too small a sample from which to derive significant conclusions. The overall percentage of articles in which appearance is mentioned is lower than we anticipated, at eleven percent for female nominees and five percent for male nominees, but we nonetheless find the data informative. Among the sixteen nominees we studied, Elena Kagan and Sandra Day O'Connor received the most media coverage of their appearance. Their appearance was mentioned in sixteen and seventeen percent of the articles, respectively. Notably, articles written about Kennedy, Scalia, and Powell during the introduction week included no mention of their appearance.

We observed disparate gendered treatment of appearance not just in the number of articles but also in the context in which appearance is discussed. For the female nominees, appearance is likely to be couched in terms of, or connected to, their qualifications, illustrating a version of the competence/appearance double bind. One example of reporting on appearance as a qualification occurred during the Miers nomination. Reporters noted that "Miers enjoys the absolute confidence of the president, who once called her 'a pit bull in size 6 shoes"' and that in her youth, "Harriet was blond, pretty and athletic-she captained the tennis team as a senior, and was voted 'best all around in sports'-but she was known as more serious than social. While the cool girls wore bouffant hairdos, she wore a long braid wound modestly around her head." 269 As another example, in an article conveying the excitement related to Sotomayor's nomination from individuals in her native Puerto Rico, one author conveyed that "Miss Puerto Rico gushed that Judge Sotomayor's selection by President Obama proved that the island's women were not just beautiful." 270 It is difficult to extract from this comment whether this is a "compliment," transcending the either/or dichotomy of the double bind facing women about appearance-that, indeed, Sotomayor is smart and beautiful - or whether the comment is more of an affront, suggesting that, in fact, there are smart Puerto Rican women, like Sotomayor, in addition to the beautiful ones. Either way, this news coverage suggests a complexity, as we allude to in our literature review, on issues of appearance and competence.

For the male nominees, who also receive media attention surrounding their appearance, the reporting is less connected to their qualifications or intelligence. Consider an article written about Breyer, for example, that highlights his quirky clothing preferences: "While working for the Senate Judiciary Committee, he once wore the same suit, torn under the armpit, for six weeks running. His sweaters have holes in them and his collars are frayed, even though his net worth is at least $\$ 3.6$ million." 271 Here, Breyer's offbeat fashion sensibility is definitely criticized, but offset and contextualized with his financial situation. Or take one of the first articles

269. Grunwald et al., supra note 253.

270. Damien Cave, In Puerto Rico, Supreme Court Pick With Island Roots Becomes a Superstar, N.Y. Times, May 30, 2009, at A9.

271. David Margolick, Man in the News: The Supreme Court; Scholarly Consensus Builder: Stephen Gerald Breyer, N.Y. TIMES, May 14, 1994, § 1, at 1. 
announcing President Bush's selection of Souter: “Judge Souter, a slight man wearing a gray pinstripe suit and conservative navy blue tie, looked alternately bemused and solemn as Mr. Bush fielded questions about the judge's position on abortion." $272 \mathrm{~A}$ second article reported that "[1]awyers here can tell you .... what he wears (his black judge's robe was said to add color to his attire)." ${ }^{273}$ Discussion of Souter's attire in both articles is descriptive, conveying the stereotypical image of what a judge is supposed to look like-wearing a conservative suit or black judicial robe.

We also coded for the presence of a photograph to test the appearance hypothesis. This variable was dichotomously coded. Unlike the other variables, this variable does not speak directly to how members of the press perceive components of appearance and their importance to the nominee. It does, however, indicate that photographic representations of nominees are important to the narrative of the article. In this way, the presence of photographs supported the general hypothesis. Of the total number of articles written about female nominees, forty-two percent included a photograph. Articles about male nominees, however, included a photograph only thirty percent of the time. An independent $t$-test indicated that this difference was statistically significant $(t=3.31, p<0.001)$. We did not engage in analysis of the content of the photographs themselves, but anecdotal observations suggest that women are depicted in a less flattering light than men and lead us to suspect that the results of such a study would be revealing.

Preliminary Finding 4: The limited sample of articles from the introduction week reveals that the family life of female nominees tends to be mentioned more frequently than the family life of male nominees, but more data is needed.

To capture the media's portrayal of family status, we focused our analysis on two interwoven, defining measures of family: marriage and parenthood. Specifically, we were interested in how the media coverage portrayed the marital status (whether a nominee was married or single or widowed) and parental status (whether the nominee was a parent or childless) of each nominee, and coded the articles to capture these two variables.

Under the umbrella of family life, we found that marital status was mentioned at nearly the same frequency for male and female nominees, whereas parental status was mentioned with slightly more frequency for female nominees than male nominees. ${ }^{274}$ As with Preliminary Finding 3, more data is necessary to assess these variables because they were mentioned so infrequently during the introductory period. ${ }^{275}$ Again, although

272. Maureen Dowd, Souter, New Hampshire Judge, Named by Bush for High Court; No 'Litmus Test,' President Says, N.Y. TimES, July 24, 1990, at Al.

273. David Margolick, Bush's Court Choice; Ascetic at Home but Vigorous on Bench, N.Y. TIMES, July 25,1990 , at Al.

274. See infra Table 5 for data relating to the frequency of mentions of nominee family life by nominee sex.

275. $t=0.54, p=0.593$. The low mean score ( 1.21 for females, 1.19 for males) indicates that this variable was barely mentioned during the introductory period for either male or female nominees. 
not statistically significant due to the limited sample, we did observe trends that merit further exploration during subsequent phases of research.

\section{Marital Status}

Marital status is mentioned in sixteen percent of the articles written about the female nominees and thirteen percent of the articles written about the male nominees. This is consistent with Kathleen Hall Jamieson's study of print coverage on federal elections featuring women in 1990, 1992, and 1993, where she found that "women in political articles are identified in spousal or parental roles more often than men." 276 Our qualitative analysis of the articles further revealed that when marital status is mentioned, there is often a gendered characterization. For female nominees, the coverage focuses more frequently on the spousal obligations of a nominee who is also a wife, rather than merely a mention of marital status in passing (which is more commonly the case for male nominees). For example, in "The Man Behind the High Court Nominee," a reporter for the New York Times wrote that "[e]ven though she had established an extraordinary record as a lawyer and teacher, Ms. Ginsburg has acknowledged that without the strong personal and political support of her husband, she may never have become President Clinton's choice for the Supreme Court."277 In the Washington Post, Ginsburg's husband was named "The Spouse of Ruth; Marty Ginsburg, the Pre-Feminism Feminist." 278 Among the more interesting passages from this article is a reflection on Ginsburg's skills as a new wife, describing her as a "complex young woman with large ambitions, [who] placed a lumpy mass of tortured protein on a plate in front of the person she had recently married," insisting it was "tuna fish casserole." 279

The reporting on female nominees' marital status also reinforces stereotypes. For example, an article on O'Connor observed that "[ $t$ ]he job wasn't something she or her family needed. They were already respected and well-heeled. They enjoyed what everyone, including her husband, an attorney with one of Phoenix's most prestigious corporate law firms, describes as a comfortable family life." 280 This article suggests that as a well-to-do wife, she did not desire a more powerful career. Other articles also focused on her balancing of the homemaker/career bind. One observed that " $[t]$ he couple's relationship is thought to be so harmonious that they were once asked to put on a skit for a group of women bankers called 'how to combine two successful careers and a successful marriage in 199 steps." 281 Another noted that "[w]hile Judge O'Connor is most often described as a diligent, nononsense [sic] woman, always ready to move up the next notch of success, close friends say that in private she talks frankly

276. JAMIESON, supra note 29 , at $169-70$.

277. Stephen Labaton, The Man Behind the High Court Nominee, N.Y. TmES, June 17, 1993, at A1.

278. Jay Mathews, The Spouse of Ruth; Marty Ginsburg, the Pre-Feminism Feminist, WaSH. POST, June 19,1993 , at B1.

279. Id.

280. Barbash \& Gup, supra note 245.

281. Id. 
of working hard to be both a successful public figure and a successful wife and mother." 282

By comparison, with male nominees, marital status is noted primarily as basic biographic information. For example, the New York Times reported that Kennedy "has been married to the same woman for 24 years, has sent all three of his children to his alma mater, Stanford University, and lives in the same white colonial-style house in Sacramento, behind a camelia [sic] bush and a neat row of gardenias, where he was born 51 years ago." ${ }^{283}$ Similarly, for Thomas, the New York Times reported that "his first marriage, from which he has one son, Jamal, began to come apart. He has since married Virginia Lamp, who works on legislation for the United States Labor Department." 284

The Media Study results for nominees without spouses are also notable. Only four nominees to the Court since the early 1970s have been unmarried: Souter, Miers, Sotomayor, and Kagan. Interestingly, for Souter, marital status was mentioned in fifteen percent of the articles, compared to nine percent for Miers, five percent for Sotomayor, and sixteen percent for Kagan. More revealing, perhaps, than the data on this point is the tone of the headlines as well as the articles themselves, which evidence a different treatment for female nominees without a spouse. For example, the media focused on Miers's single status, including references to her "girls' nights out"285 and one article reporting that " $[\mathrm{h}] \mathrm{er}$ red Mercedes-Benz was such a fixture in the West Wing lot that colleagues called it an abandoned car; she has never married or had children, and some of her friends believe she has sacrificed her personal life for work." 286

Or consider as another example the article "Sotomayor: A Single Supreme?," which reported, with exuberance, that there was yet "[a]nother first on the Supreme Court! If Sonia Sotomayor is confirmed, she'll be its first . . . bachelorette." 287 The article goes on to describe her first failed "college marriage," her subsequent "fizzled" engagement to Peter White, and her current single status. ${ }^{288}$ The author projects pity on Sotomayor: "Who's going to accompany her to those fancy White House dinners?"289 Another article appearing in the New York Times, titled "A Trail Blazer and a Dreamer," reported that Sotomayor, "[d]ivorced and with no children, ... [she] enjoys the ballet and theater." 290 The Washington Post ran the headline "Friends Provide Glimpse Into Nominee's 'Very Full Life,"” noting that, "[a] 54-year-old divorced

282. B. Drummond Ayres, Jr., Woman in the News; 'A Reputation for Excelling', N.Y. TIMES, July 8, 1981 , at A1.

283. Robert Reinhold, Man in the News; Restrained Pragmatist Anthony M. Kennedy, N.Y. TIMES, Nov. 12,1987 , at Al.

284. Neil A. Lewis, The Supreme Court: Man in the News; From Poverty to the Bench; Clarence Thomas, N.Y. TimES, July 2, 1991, at A1.

285. Purdum \& Lewis, supra note 251.

286. Grunwald et al., supra note 253.

287. Amy Argetsinger \& Roxanne Roberts, Sotomayor: A Single Supreme?, WASH. POST, May 27, 2009, at $\mathrm{C} 03$.

288. Id.

289. Id.

290. Sheryl Gay Stolberg, A Trailblazer and a Dreamer, N.Y. TIMES, May 27, 2009, at A1. 
woman who never had children, Sotomayor is said to be a workaholic who fills her free time with a huge network of close friends, extended family members, colleagues, former classmates and just about anyone else who has entered her circle." ${ }^{291}$ The article went on to cite friends as saying that "[o]ut of deference to her privacy, the one topic [of] Sotomayor's [they] won't discuss is her personal relationships."292 But the reporters made sure to confirm "that Sotomayor 'does date." "293

The novelty of the nomination of the first single woman to the Supreme Court did not wear off even after Sotomayor was confirmed. The headline, "Then Comes the Marriage Question," appeared during Kagan's nomination. ${ }^{294}$ The author wrote:

Here we go again.

For the second time in a year, a childless, unmarried woman in her $50 \mathrm{~s}$ has been nominated to be a justice on the Supreme Court and the critics have come out swinging. This time Elena Kagan, the former dean of Harvard's law school, who is now solicitor general, has been described as having sacrificed a home and personal life in her quest for a brilliant legal career. ${ }^{295}$

Another article went a step further, beyond just acknowledging the sacrifice that Kagan made for her career. Instead, the way her unmarried status was characterized is reminiscent of the double binds that confront women; in this case, the message is that a woman can be smart or married, but not both at the same time. "She really is a thinker," a colleague said. ${ }^{296}$ "She is not married and she doesn't have family in her life. Her books are, in many ways, her companions. She has a lot of friends. But she's lived alone, and the world of books and ideas is her world."297

In contrast, of Souter's decision not to marry, media coverage during the introduction week referenced his marital status primarily in the context of responding to criticism that he might not be empathetic to women's issues, as seen in the following headline: "Former Souter Girlfriend Says He's Fair-Minded."298 The article quoted his former girlfriend as stating, "[h]aving never married, I know everyone is wondering does he have the empathy to understand women's issues, and I think he would. It's not as though he has lived in a cave for the last 25 years." ${ }^{299}$ A second headline questioned "Does Souter Have Heart?," with the reporter characterizing him as "[a] loner, but not lonely, and not without humor, he's invariably described as an independent man, never married, who lives alone and keeps his own counsel." 300

291. Keith B. Richburg et al., Friends Provide Glimpse into Nominee's 'Very Full Life', WASH. Post, May 31, 2009, at A08.

292. Id.

293. Id.

294. Holson, supra note 16.

295. Id. (paragraph break omitted).

296. Amy Goldstein et al., A History of Pragmatism Over Partisanship, WASH. POST, May 11, 2010, at A01.

297. Id.

298. Judy Mann, Former Souter Girlfriend Says He's Fair-Minded, WASH. POST, July 27, 1990, at C3.

299. Id.

300. Haynes Johnson, Does Souter Have Heart?, WASH. POST, July 27, 1990, at A1. 


\section{Parental Status}

We expected to find that that the parental status of nominees would be mentioned more frequently for female nominees than male nominees. Contrary to these expectations, our quantitative analysis revealed that parental status was actually mentioned with the same frequency for both male and female nominees (in exactly eight percent of all articles regardless of gender). As with marital status, a significant difference in media coverage between male and female nominees was observed in our qualitative analysis, specifically in the nuanced ways through which parental status is reported.

Recent headlines have been explicit in evaluating, scrutinizing, and criticizing the nominees based on issues of motherhood (or nonmotherhood, as in the case of three female nominees). For example, six days after President Obama announced Kagan's nomination, the Washington Post ran an article by reporter Ann Gerhart with the following headline: "The Case for More Mothers." ${ }^{01}$ The story articulates how alive and well the maternal double bind continues to be, even a decade into the twenty-first century:

Motherhood offers a one-word verifier. It signals a woman with an intensity of life experiences, jammed with joys and fears, unpredictability and intimacy, all outside the workplace. Much of the time, it's the opposite of being strategic and assiduously prepared. ${ }^{302}$

Two days later, the New York Times ran an article entitled "Judging Women," in which author Lisa Belkin observed:

If Elena Kagan is confirmed by the Senate, there will be three women on the Supreme Court for the first time. This is a measure of how far women have come. Two will be single and childless. This may be a measure of something else entirely. ${ }^{303}$

It should be acknowledged that the media also mentioned Souter's lack of children, but the coverage was not nearly as pervasive or as bound up in the success of his career. ${ }^{304}$

Notably, none of the male nominees' domestic abilities, such as cooking skills, received news coverage. By contrast, the media reported that O'Connor enjoyed a reputation as "an excellent cook and a lover of fine wines"305 and that Ginsburg was "phased ... out of the kitchen at a relatively early age" because her children found their father to be a better cook. ${ }^{306}$ Likewise, Miers was reported to be "a terrible cook." 307

301. Gerhart, supra note 17.

302. Id.

303. Lisa Belkin, Judging Women, N.Y. TIMES, May 23, 2010, at MM11.

304. See supra notes 287-304 for a comparison of the media coverage of Souter's marital and parental status with that of Sotomayor and Kagan.

305. John M. Crewdson, Nominee for High Court: A Record Defying Labels, N.Y. TIMES, July 12, 1981, $\S 1$, at 1 .

306. Guy Gugliotta \& Eleanor Randolph, A Mentor, Role Model, and Heroine of Feminist Lawyers, WASH. POST, June 15, 1993, at A14.

307. Grunwald et al., supra note 253. 
Both O'Connor and Ginsburg also were described with strong stereotypical metaphors related to their roles as mothers. For example, the New York Times reported that " $[\mathrm{w}]$ hile Judge O'Connor is most often described as a diligent, nononsense [sic] woman, always ready to move up the next notch of success, close friends say that in private she talks frankly of working hard to be both a successful public figure and a successful wife and mother." ${ }^{308}$ The Washington Post called Ginsburg "motherly enough for traditionalists." ${ }^{309}$ And an op-ed in the New York Times speculated about "whether Ruth Bader Ginsburg had paid taxes for her household help and whom she'd hired to care for her two children." 310

When male nominees' parental status is discussed, it tends to be mentioned in passing and not as a newsworthy topic warranting lengthy discussion. For example, when Scalia's fatherhood was referenced, the coverage appeared briefly in connection with his views on abortion: "A Roman Catholic who is the father of nine children, Scalia is personally opposed to abortion." 311 No article appearing during the introduction week reported on Scalia's ability to balance his parenting obligations as a father of nine children with a successful career. When a male nominee's parental status is covered in detail, it is portrayed as a credential or it is portrayed in the context of reporting on the nominee's spouse. For example, in a story on Alito's parental status, a reporter observed:

As a parent, Judge Alito appears to follow his parents' model. Hilary Monaco, a friend and neighbor, said she and Judge Alito spent many hours coaching the high school mock trial team. He taught the students, including his son, Philip, the rules of evidence and how to write opening and closing statements. In 2001, the team made it to the county semifinals-its best performance, she said. ${ }^{312}$

An article on Roberts's difficulties having children was couched entirely in terms of his wife, Jane Sullivan. The article, "Nominee's Wife is a Feminist After Her Own Heart," reported that by the time Sullivan and Roberts married, "she was 42 , and Catholic doctrine prohibits most forms of fertility treatment. She and her husband went through an "uncertain difficult period where she wanted badly to have children," before they eventually adopted two infants. ${ }^{313}$ The article closed by noting that during the week after Roberts's nomination was announced, Sullivan, "a litigator [who] then moved on to the highly technical field of satellite procurement," found herself "too busy to go into the office." 314 As with Scalia (and the other male nominees), no article covered the challenge for Roberts of balancing his career and his responsibilities as a father of two young children.

308. Ayres, supra note 282.

309. Mary McGrory, Clinton Unbridled, WASH. Post, June 17, 1993, at A2 (also noting that she was "daughterly about her own mother, and sisterly enough to delight all but fanatical feminists").

310. Anna Quindlen, Public \& Private; Ban the Bollix, Bill, N.Y. TIMES, June 16, 1993, at Al5.

311. Ruth Marcus, Judge a Favorite with Conservative Lawyers, Activists, WASH. POST, June 18, 1986, Al.

312. Janny Scott, Court Choice Conservative by Nature, Not Ideology, N.Y. TIMES, Nov. 7, 2005, at A1.

313. Hanna Rosin, Nominee's Wife is a Feminist After Her Own Heart, WASH. Post, July 22, 2005, at C01.

314. Id. (minor punctuation omitted). 


\section{Preliminary Finding 5: The articles are more likely to be written by male journalists than female journalists during the introduction week.}

Although this finding may appear somewhat tangentially related to our Media Study, which focuses foremost on the nominees themselves, we wondered specifically about who is actually constructing and framing the gendered media messages we observed. Is there a gendered framework surrounding the coverage of nominees to the Court? One way to assess this is to examine the extent to which male and/or female reporters and writers are writing about the nominations. It turns out that indeed, as we expected, there are patterns of gender inequality in journalism generally, as we discussed in the foregoing literature review. Specifically, however, our data reveals that, overall, the majority of the articles about Supreme Court nominees during the introductory week are written by men. Women authored a total of twenty-two percent of the total articles and opinion pieces we coded, whereas men authored over sixty percent. ${ }^{315}$

Article authorship was measured using three variables to account for the first, second, and third authors of an article. Articles in which no author was explicitly stated due to wire service use or a name not being listed in the byline were excluded from analysis. One-sample t-tests were then performed, with a 0.5 proportion used as the test value. ${ }^{316}$ Results indicate that for articles with named authors, the hypothesis that male journalists more often authored articles was supported. Male journalists were more likely to be first authors $(n=641, t=14.88, p<0.000)$ and second authors $(n=132, t=4.68$, $\mathrm{p}<0.000$ ) of the articles. Although there was not a statistically significant difference for the third author position $(n=29, t=0.55, p=0.59$ ), this is less important, as the majority of articles with named authors have primarily one or two authors.

We considered whether this outcome may be attributable to the fact that our Media Study reaches back to the early 1970 s, a time when women did not comprise a significant portion of the workforce, particularly in journalism. To test this, we completed a separate analysis of article authorship going back until just 1990 . Somewhat surprisingly, from 1990 to 2010 , only twenty-four percent of the articles were authored by women, just two percentage points more than the dataset for the full time period from 1971 to 2009 . Further, when we look specifically at how the authorship of the articles breaks down by nominee, we did not observe an obvious pattern or trend toward more female authors as we moved forward in time. Interestingly, articles about Ginsburg and Kagan were authored most frequently by female journalists (forty-one and forty-two percent, respectively), whereas articles about Sotomayor were authored by female journalists relatively infrequently (eighteen percent of the time).

This finding is important to understand the context of the media framework in which the coverage of nominees occurred. But it does not automatically signal, nor are we suggesting, that female journalists necessarily portray the nominees in a more

315. In eighteen percent of the articles there was no author listed. These articles were subsequently coded as "author unknown" and we were unable to make a determination of the author's gender.

316. See infra Table 2 for the results of our analysis on the differences of authorship by author position. 
positive or less gendered way. It is similar to our unwillingness to assume that female judges automatically adjudicate from a feminist standpoint, although we argue unequivocally that having broader, more equitable gender representation-on the bench or in the newsroom-is an important goal.

Headline tone was also examined, and a more thorough investigation of this variable will be conducted in subsequent phases of this research. ${ }^{317}$ Initial analysis conducted using a chi-square test indicates that there is a statistical relationship between nominee sex and headline tone. Male nominees tend to receive more neutral coverage, which in this study was defined as lacking judgment statements. As an example, when Alito was nominated, a New York Times article headline read, "Bush Picks U.S. Appeals Judge to Take O'Connor's Seat." 318 Conversely, female nominees received more negative, positive, and mixed coverage. For example, an article entitled "The Supreme Court: Woman in the News; Rejected as a Clerk, Chosen as a Justice: Ruth Joan Bader Ginsburg"319 appeared in the New York Times; an opinion piece entitled "Double Standard; Funny How the Achievements on Sonia Sotomayor's Resume Suddenly Count for So Little" appeared in the Washington Post ${ }^{320}$ And during the most recent nomination of Elena Kagan, a headline in the New York Times read, "Pragmatic New Yorker Chose a Careful Path to Washington." 321

The chi-square test results suggest that although female nominees are not always portrayed negatively, they do tend to elicit more frequent judgment statements in coverage. An additional analysis was conducted to determine if this relationship was influenced by the sex of the author. For the initial analysis, first-author sex was used. Two chi-square tests were conducted. The first was conducted on data for stories authored by males. As with the first chi-square, this relationship was statistically significant. When analyzing the female-authored stories only, however, the relationship between nominee sex and headline tone is not statistically significant, suggesting that there is not a strong relationship between these two variables. As a final analytical step, the observed frequency of the male-authored chi-square test was used as the expected frequency for the female-authored chi-square test. This relationship was once again statistically significant, suggesting that there is a statistically significant difference between the manner in which males and females cover Supreme Court nominees.

317. Future analysis will make use of more sophisticated nonparametric testing in order to provide greater statistical precision.

318. Elisabeth Bumiller \& Carl Hulse, Bush Picks U.S. Appeals Judge to Take O'Connor's Seat, N.Y. TIMES, Nov. 1, 2005, at A1.

319. Neil A. Lewis, The Supreme Court: Woman in the News; Rejected as a Clerk, Chosen as a Justice: Ruth Joan Bader Ginsburg, N.Y. TIMES, June 15, 1993, at Al.

320. Editorial, Double Standard: Funny How the Achievements on Sonia Sotomayor's Resume Suddenly Count for So Little, WASH. POST, June 2, 2009, at Al4.

321. Sheryl Gay Stolberg et al., Pragmatic New Yorker Chose a Careful Path to Washington, N.Y. TIMES, May 11, 2010, at A1. 


\section{B. Observations}

\section{The Complexities of (Non)Motherhood and Appearance/Competence}

Perhaps somewhat naively, we hoped to find that media coverage evolved since the nominations of O'Connor and Ginsburg to become less gender focused, though we speculated that this was unlikely to be the case based upon the anecdotal headlines that appeared during the nominations of Sotomayor and Kagan that inspired us to take on this Media Study in the first place. The data comparing coverage during the introduction weeks for O'Connor and Ginsburg versus Miers, Sotomayor, and Kagan is interesting. We found a significant reduction in the average number of articles about the nominees' marital status; an average of twenty-three articles for O'Connor and Ginsburg compared to an average of ten articles for the most recent female nominees. The mention of parental status similarly dropped from an average of eleven articles to an average of five articles. We also found a more modest reduction in the average number of articles related to appearance or referencing the nominees' gender, from ten to eight and fifty-four to forty-two, respectively.

Two increases are also notable. During the O'Connor and Ginsburg introduction weeks, the average number of articles referencing sexual orientation was two, compared to an average of ten articles for Miers, Sotomayor, and Kagan. The percentage of male reporters also increased, from fifty-four percent to sixty-seven percent.

Although these statistics might be cause for celebration, at least to the extent they document a reduction in the number of articles focusing on a nominee's parental/marital status, appearance, or gender, we are reluctant to take such a position. We remain concerned about the quantity and content of coverage devoted to (non)motherhood, appearance, and competence of female nominees, and we are troubled by the increased attention to the sexual orientation and marital status of single, female nominees. It is one thing to discuss a nominee's family life in the context of background, but quite another to discuss it as a (dis)qualification for becoming a Supreme Court Justice. The next phases of our research will explore these distinctions further in order to evaluate such concerns. Moreover, the results from our Media Study during the introduction week support the observations we made at the beginning of this Article, where we suggested that the double binds related to motherhood and appearance identified by Frye and Jamieson persist today but manifest in increasingly complex and difficult ways. ${ }^{322}$ We suspect that if this is the case for the women who are nominated for such a powerful legal position, it is likely true for most, if not all, women lawyers as they seek to advance in their careers.

Although male and female nominees alike received coverage about their parental status, motherhood (or nonmotherhood) took on a special role in the news reports about the female nominees. For Sotomayor, and especially Kagan, nonmotherhood was presented as a possible basis for disqualification. No male nominees were subject to a similar kind of critique based upon their decision about whether or not to become a

322. See supra Part II.A.l.c.i.-ii for a discussion of the double binds related to motherhood and appearance. 
parent. With appearance, not only did the media cover the appearance of female nominees more frequently but the nature of the coverage differed based upon gender, particularly when considering the association of appearance and competence. Our Media Study revealed ways that media scrutinizes the competency of female nominees more closely and "assessed by stricter standards than those applied to men." 323 For example, the opinion piece "The Nomination of Mrs. O'Connor" declared that "[r]arely, if ever, has a president reached so far down into the state judiciary to find a Supreme Court justice. Most of them have come from higher ranks of the judicial system, from national political positions or from the nationally known law firms." 324 The piece, although generally expressing praise for the President's pick, and acknowledging the plight of women lawyers, nonetheless fails to address O'Connor's potential for success, instead leveraging criticism against her less-than-perfect professional credentials. Contrast this criticism with another article, in which a reporter characterizes O'Connor's visits to meet senators before the confirmation hearings as if she was a debutant at a ball. ${ }^{325}$ Paula Monopoli's description of Miers' withdrawal from the nomination process is also revealing. Monopoli characterizes the withdrawal as a historical moment, highlighting the profound gender bias still at play in the nomination process and in society generally: “ $[\mathrm{N}]$ ominees are increasingly required to be 'brilliant' graduates of an elite law school and sitting United States Circuit Courts of Appeals judges. Women who are brilliant are rarely characterized as such. Rather they are described as 'hard-working,' 'good managers' or 'well-organized.",326 Of all the female nominees, the coverage of Miers's appearance was particularly harsh, especially when viewed in light of coverage about her competence.

\section{The Untold Stories of Women Not Nominated}

As we reflected upon the significance of our preliminary findings, we could not help but notice the contrast between contemporary media discourse on gender and the Supreme Court (which focuses primarily on the four women who are serving or have served as justices), and media discourse from nearly half a century ago (which focused, significantly, on women who were short-listed but not nominated). To be sure, media in the twenty-first century examines all short-listed Supreme Court candidates, male and female alike. But we became captivated by the fact that modern media quickly forgets about the other candidates once a nominee is announced, particularly in light of the fact that coverage of the Powell and Rehnquist nominations included a notable amount of press devoted to the "rejected" candidates. We also noticed that modern reporters and commentators frequently retell O'Connor's story as the first woman to serve on the Court, followed by a discussion of the three successful nominees in the wake of her legacy. Our Media Study, however, reveals an important story line that does not get retold. A decade before O'Connor's nomination, President Nixon

323. Williams, supra note 81 , at 413 .

324. Editorial, supra note 243.

325. Lynn Rosellini, Jr., Judge O'Connor Makes Courtesy Call at Capitol; Attorney General William French Smith, N.Y. TIMES, July 15, 1981, at A19 (O'Connor was asked whether her Capitol Hill rounds made her "feel a bit like a debutante, being introduced to all these people").

326. Monopoli, supra note 31 , at 62 (footnote omitted). 
contemplated a bold move; on his shortlist of nominees appeared the name of Mildred Lillie, a judge from Califomia.

Lillie ultimately was not nominated to the Court, ${ }^{327}$ but a rich media conversation about women and the Court played out on the pages of the New York Times and Washington Post, a conversation we uncovered in our research. The media reported a deflated sentiment felt by women at the time President Nixon announced his choice for the Court: "Disappointment, laced with resignation, was the mood last night among 3,000 Republican women over President Nixon's failure to appoint the first woman to the U.S. Supreme Court." 328 Another article, "President Bypasses Women for Court; Talent Pool Small," reflected on the lack of women lawyers available as candidates, speculating that females were not hired or promoted by law firms for a variety of reasons: "they'll only get pregnant and leave"; "[w]omen cannot be used in courtroom work; they are too shrill; juries do not like them"; "[w]omen just cannot stand the strain of litigation; they fall apart"; and that "[c]orporate law work requires long trips out of town, and long sessions at night in hotel rooms, writing briefs and otherwise preparing cases. The partners' wives would not stand for women in such jobs." 329

The same disappointment felt by women in 1971 was reflected in media coverage over twenty years later when President Clinton selected Stephen Breyer as his nominee to the Court. Since there were two women already serving on the Court, the appointment of a white male likely came as no surprise. Perhaps more notably, however, is the fact that there were no women who even appeared on Clinton's short list of potential nominees in 1994. An opinion piece in the New York Times illuminated this issue: "Another white male on the Court increases Mr. Clinton's obligation to bring more women and racial minorities into the selection process in the future. We find it hard to believe there were no qualified candidates in these categories good enough to make the finals this time." 330

After learning of Mildred Lillie's failed nomination, we became curious about her story and those of other women who were short-listed but never nominated to the Court. We discovered that until President Obama took office (and subsequently nominated two women to the Court, making $100 \%$ of his nominations women), a total of fourteen women were formally short-listed, the first being Soia Mentschikoff in

327. Lillie's fate was determined by the American Bar Association's Committee on the Federal Judiciary, which deemed her unqualified to serve on the Court. See James M. Naughton, Early Vote Asked: President Asserts His Nominees Epitomize Conservative Views, N.Y. TIMES, Oct. 22, 1971, at 1. President Nixon's counsel during the nomination process, John Dean, later stated in an interview that

Mildred Lillie was every bit, if not more, qualified to be a Justice than Day O'Connor. But what happened was the American Bar Association at that time was made up of all men and the old boys did not think that it was time for a woman to be on the high court. But the principal person who really objected to Nixon selecting a woman was none other than the Chief Justice himself, Warren Burger, who threatened that he would resign if Nixon put a woman on the court.

American RadioWorks, Interview by Kate Ellis with John Dean, AM. PUB. MEDIA, http://Americanradioworks. publicradio.org/features/prestapes/johndean.html (last visited Mar. 5, 2012) (paragraph break omitted).

328. Dorothy McCardle, GOP Women: Resigned, WASH. POST, Oct. 22, 1971, at B2.

329. Shanahan, supra note 49.

330. Editorial, Another New Justice, N.Y. TIMES, May 14, 1994, at 20. 
1965 by President Johnson. ${ }^{331}$ But these women were not nominated, and their stories have gone largely untold. We intend to bring their stories to life through a forthcoming project inspired by our Media Study. ${ }^{332}$

It is also noteworthy that in the Nixon era, the media discourse reflected fairly explicit bias, contemplating whether a woman ought to serve on the Court in the first place or whether a qualified woman might even exist to assume such a powerful position. Today, illustrated most recently by the nominations of Sotomayor and Kagan, such explicit bias is just about nonexistent. It has been replaced, however, with more subtle shades of bias that tend to center around often interrelated issues of motherhood, competency, and appearance. The pervasiveness of these three kinds of bias is evidenced in the first phase of our Media Study, and we predict that our subsequent research will offer further support.

\section{CONCLUSION}

"[T]he first step in getting power is to become visible to others . . ." Sandra Day O'Connor ${ }^{333}$

Perhaps no other female lawyer is better situated to offer guidance on the acquisition of power within the profession than O'Connor. In an era where women simply did not exist in the legal profession, let alone hold positions of power, she adeptly navigated the power pipeline as an editor of the Stanford Law Review, as the first female majority leader in the Arizona state senate, and, ultimately, as the first woman Supreme Court Justice. She connects visibility with power. But what does it mean to be visible? Are women now visible in the legal profession given that they comprise half of law graduates? Are women now visible in the profession given that they comprise one-third of the Supreme Court Justices? If the answer to both of these questions is yes, then why do women remain disproportionately excluded from the legal profession's positions of power? We submit that the relationship between visibility and power is complex, and power is not achieved merely by being present.

The results from Phase One of our research, focusing exclusively on the nominee's introduction to the public by the press, reveal an ongoing struggle for equal access to and ascension in the power pipeline for women in the legal profession that is linked to motherhood, appearance, and competence. This revelation, which emerges during the limited window of the nominees' introductory weeks, invites further study. We anticipate similar if not even more illuminating results during the next phases of our Supreme Court Media Study. We conclude that the media depiction of Supreme Court nominees offers an alternative, valuable mechanism for evaluating gender equality in the legal profession's pipeline to power.

331. See NEMACHECK, supra note 186 , app. at 150.

332. We will explore the stories of these women in a forthcoming work, tentatively titled Not Nominated. We see this work as responsive to Kathleen Hall Jamieson's call for "recovering" as a solution to the double binds faced by women in leadership. She writes: "Recovery of the history of women's lives and accomplishments reminds us of the progress women have made and the means they have employed." JAMIESON, supra note 29 , at 191.

333. SANdra Day O'Connor, The Majesty of the Law, ReFlections of a Supreme Court Justice 201 (Craig Joyce ed., 2003). 


\section{APPENDIX}

Table 1. List of Nominees, Nomination Period, and Number of Articles Appearing During the Introduction Week

NUMBER OF ARTICLES DURING INTRODUCTION WEEK

\begin{tabular}{|c|c|c|c|c|}
\hline NOMINEE & President & $\begin{array}{c}\text { ANNOUNCEMENT } \\
\text { DATE } \\
\end{array}$ & $\begin{array}{c}\text { CONFIRMATION } \\
\text { DATE/WITHDRAWAL }\end{array}$ & $\begin{array}{c}\text { TOTAL } \\
\text { ARTICLES }\end{array}$ \\
\hline Kagan & Obama & May 10,2010 & Aug. 4,2010 & 57 \\
\hline Sotomayor & Obama & May 27, 2009 & Aug. 6, 2009 & 78 \\
\hline Alito & Bush & Nov. 1, 2005 & Jan. 31,2006 & 68 \\
\hline Miers & Bush & Oct. 4,2005 & Oct. 28,2005 & 62 \\
\hline Roberts & Bush & July 19,2005 & Sept. 6, 2005 & 98 \\
\hline Breyer & Clinton & May 13,1994 & July 29,1994 & 26 \\
\hline Ginsburg & Clinton & June 14,1993 & Aug. 3, 1993 & 44 \\
\hline Thomas & Bush & July 1,1991 & Oct. 15,1991 & 57 \\
\hline Souter & Bush & July 23, 1990 & Oct. 2, 1990 & 55 \\
\hline Kennedy & Reagan & Nov. 11,1987 & Feb. 3, 1998 & 25 \\
\hline Bork & Reagan & July 1,1987 & Oct. 23,1987 & 43 \\
\hline Scalia & Reagan & June 18,1986 & Sept. 17,1986 & 44 \\
\hline O'Connor & Reagan & July 7,1981 & Sept. 21, 1981 & 30 \\
\hline Stevens & Ford & Nov. 28,1975 & Dec. 17,1975 & 21 \\
\hline Powell & Nixon & Oct. 22,1971 & Dec. 10,1971 & 29 \\
\hline Rehnquist & Nixon & Oct. 22,1971 & Dec. 6, 1971 & 37 \\
\hline
\end{tabular}


TABLE 2. DIFFERENCES OF AUTHORSHIP BY AUTHOR POSITION

\begin{tabular}{ccccc}
\hline Author Position & Mean (SD) & Mean Difference & t-value & df \\
\hline First & $0.754(0.43)$ & 0.254 & $14.881^{* * *}$ & 640 \\
Second & $0.689(0.46)$ & 0.189 & $4.684^{* * *}$ & 131 \\
Third & $0.552(0.51)$ & 0.052 & 0.550 & 28 \\
\hline
\end{tabular}

Note. $^{* * *} \mathrm{p}<0.001$, two-tailed. Authors were dummy coded with female $=0$. Test Value was 0.5 .

TABLe 3. Number of STORIES AND Word COUNT By NomineE SEX

\begin{tabular}{ccccc}
\hline & $\begin{array}{c}\text { Female } \\
\text { Mean(SD) }\end{array}$ & $\begin{array}{c}\text { Male } \\
\text { Mean(SD) }\end{array}$ & $\begin{array}{c}\text { Mean } \\
\text { Difference }\end{array}$ & t-value(df) \\
\hline $\begin{array}{c}\text { Number of } \\
\text { Stories } \\
\text { Word Count } \\
\text { per Story }\end{array}$ & $54.2(18.2)$ & $47.7(23.1)$ & 6.5 & $0.546(13)$ \\
\hline Note. ${ }^{*}$ p $<0.05$, two-tailed. $\nmid$ Nominees without this variable removed from analysis
\end{tabular}

Table 4. Mentions of Nominee ApPEARANCE by Nominee SeX

\begin{tabular}{ccccc}
\hline & $\begin{array}{c}\text { Female } \\
\text { Mean(SD) }\end{array}$ & $\begin{array}{c}\text { Male } \\
\text { Mean(SD) }\end{array}$ & $\begin{array}{c}\text { Mean } \\
\text { Difference }\end{array}$ & t-value(df) \\
\hline $\begin{array}{c}\text { General } \\
\text { Appearance }\end{array}$ & $1.10(0.392)$ & $1.08(0.358)$ & 0.027 & $0.914(656)$ \\
Adornment & $1.03(0.191)$ & $1.04(0.260)$ & 0.014 & $-0.751(656)$ \\
Physical Traits & $1.08(0.347)$ & $1.05(0.265)$ & 0.036 & $1.419(474.3)$ \\
Body Posture & $1.01(0.149)$ & $1.01(0.134)$ & 0.005 & $-0.487(656)$ \\
Picture Present & $1.42(0.502)$ & $1.31(0.426)$ & 0.108 & $2.771(530.8)^{* * *}$ \\
\hline
\end{tabular}

Note. ${ }^{* * *} \mathrm{p}<0.001$, one-tailed.

Table 5. Mentions Of Nominee Family LifE by Nominee SEX

\begin{tabular}{ccccc}
\hline & $\begin{array}{c}\text { Female } \\
\text { Mean(SD) }\end{array}$ & $\begin{array}{c}\text { Male } \\
\text { Mean(SD) }\end{array}$ & $\begin{array}{c}\text { Mean } \\
\text { Difference }\end{array}$ & t-value(df) \\
\hline $\begin{array}{c}\text { Marital } \\
\text { Status }\end{array}$ & $1.21(0.588)$ & $1.20(0.538)$ & 0.011 & $0.239(657)$ \\
$\begin{array}{c}\text { Parental } \\
\text { Status }\end{array}$ & $1.10(0.410)$ & $1.06(0.276)$ & 0.045 & $1.568(433.2)$ \\
\hline
\end{tabular}

Note. ${ }^{*} \mathrm{p}<0.05$, one-tailed. 
